\title{
Single Electron Transfer-Degenerative Chain Transfer Living Radical Polymerization of N-Butyl Acrylate Catalyzed by Na2S2O4 in Water Media
}

\author{
JORGE F. J. COELHO,,$^{1,2,3}$ ANA M. F. P. SILVA, ${ }^{2}$ ANATOLIY V. POPOV, ${ }^{4}$ VIRGIL PERCEC, ${ }^{3}$ \\ MARIANA V. ABREU, ${ }^{1}$ PEDRO M. O. F GONÇALVES, ${ }^{1}$ M. H. GIL $^{2}$ \\ ${ }^{1}$ Cires S A-Companhia Industrial de Resinas Sintéticas, Apartado 20, Samoqueiro—Avanca, 3864-752 Estarreja, Portugal \\ ${ }^{2}$ Chemical Engineering Department, University of Coimbra, Pólo II, Pinhal de Marrocos, 3030-290 Coimbra, Portugal \\ ${ }^{3}$ Roy and Diana Vagelos Laboratories, Department of Chemistry, University of Pennsylvania, Philadelphia, Pennsylvania \\ 19104-6323 \\ ${ }^{4}$ Department of Radiology, University of Pennsylvania, Philadelphia, Pennsylvania 19104-6323
}

Received 29 December 2005; accepted 6 February 2006

DOI: 10.1002 / pola.21389

Published online in Wiley InterScience (www.interscience.wiley.com).

\begin{abstract}
Living radical polymerization of $n$-butyl acrylate was achieved by single electron transfer/degenerative-chain transfer mediated living radical polymerization in water catalyzed by sodium dithionate. The plots of number-average molecular weight versus conversion and $\ln [M]_{0} /[M]$ versus time are linear, indicating a controlled polymerization. This methodology leads to the preparation of $\alpha, \omega$-di(iodo) poly (butyl acrylate) ( $\alpha, \omega$-di(iodo)PBA) macroinitiators. The influence of polymerization degree ([monomer]/[initiator]), amount of catalyst, concentration of suspending agents and temperature were studied. The molecular weight distributions were determined using a combination of three detectors (TriSEC): right-angle light scattering (RALLS), a differential viscometer (DV), and refractive index (RI). The methodology studied in this work represents a possible route to prepare well-tailored macromolecules made of butyl acrylate in an environmental friendly reaction medium. Moreover, such materials can be subsequently functionalized leading to the formation of different block copolymers of composition ABA. (C) 2006 Wiley Periodicals, Inc. J Polym Sci Part A: Polym Chem 44: 2809-2825, 2006
\end{abstract}

Keywords: butyl acrylate; degenerative chain transfer; living polymerization; single-electron-transfer; telechelics

\section{INTRODUCTION}

$\operatorname{Poly}(n$-butyl acrylate) is used in an enormous range of day life applications because of its low glass transition temperature and durability. Its applications include adhesives, coatings, leather,

Correspondence to: J. F. J. Coelho (E-mail: jcoelho3@ eq.uc.pt)

Journal of Polymer Science: Part A: Polymer Chemistry, Vol. 44, 2809-2825 (2006) () 2006 Wiley Periodicals, Inc. textiles, part of copolymers improving the soft segments in thermoplastics elastomers, among others. This potential justifies the growing interest in the development of new methodologies that allow the control of the final structure and the polymer architecture of this polymer. The developed routes to polymerize acrylates with controlled architectures were traditionally based on the ionic processes which are extremely difficult to control, at least when compared to the 
radical process. ${ }^{1,2}$ The free radical polymerization is the main process to prepare polyacrylates, in spite of the difficulty to control the polymerization leading to poorly defined products. The recent developments of new technologies based on living radical polymerization (LRP) are changing this scenario, by making it possible to establish methodologies that allow the synthesis of polymers with predetermined molecular weight, functional chain ends, narrow molecular weight distribution and complex architectures, using at the same time a radical process. The fact that the most currently developed LRP methodologies are tolerant to water is one of the main reasons why so many works are being published related to the development of LRP methodologies. The BA has been polymerized via atom transfer radical polymerization (ATRP), ${ }^{3,4}$ nitroxide-mediated polymerization, ${ }^{5}$ and stable free radical polymerization. ${ }^{6}$ Nevertheless, the LRP of BA in aqueous media under large scale feasible industrial conditions remains a challenging task. The study and development of LRP methodologies that use inexpensive commercially available compounds is extremely important to allow the industrial implementation of this process.

The aim of the present work is to study and optimize the polymerization of BA by single electron transfer-degenerative chain transfer mediated living radical polymerization (SET-DTLRP). This methodology provides the reversible activationdeactivation step required to accomplish LRP by combination of competitive SET and degenerativechain transfer. Discovered by Percec et al. ${ }^{7-9}$ this strategy has proved to be effective in the polymerization of activated ${ }^{10,11}$ and nonactivated monomers. ${ }^{7-9,12-14}$ This work presents a reliable methodology to prepare PBA with active chain ends and controlled macromolecular structure under large scale industrial conditions. The $\operatorname{poly}(n-\mathrm{BA})$ solutions in THF were also characterized by multidetector size chromatography (TriSEC), determining by this way the relationship between the intrinsic viscosity versus molecular weight and radius of gyration versus molecular weight offering valuable information about the molecular structure.

\section{RESULTS AND DISCUSSION}

\section{Simplified Mechanism}

The simplified mechanism involved in the SETDTLRP $^{9}$ of $n$-BA is presented in Scheme 1.
The SET-DTLRP provides the reversible activation-deactivation step required to carry out the LRP mechanism using a combination of competitive single electron transfer (SET) and degenerative chain transfer degenerative transfer (DT) mechanism. ${ }^{9}$ The iodoform is reduced (eq 3 ) by the $\mathrm{SO}_{2}^{--}$radical anion, which is formed from the dissociation of $\mathrm{S}_{2} \mathrm{O}_{4}{ }^{2-}$ (eqs 1 and 2), leading to the formation of radical $\mathrm{CHI}_{2}^{\circ}$. The other main reaction steps of this mechanism include the propagation (eqs 4 and 8), degenerative chain transfer to initiator or dormant species (eqs 5, 7, 9, and 10), activation of dormant species mediated by radical anion $\mathrm{SO}_{2}^{--}$ (eq 6) and termination by recombination (eq 11). Although because of the terminal iodine positions $\sim \mathrm{CHIC}(\mathrm{O}) \mathrm{OBu}$ when the termination by recombination occurs, the polymer chains continue to grow leading to a final molecular higher than expected (product of eq 11). It is necessary to note that the functionality of poly(BA) remains 2.0 even if radical dimerization occurs because the resulting polymer continues to have two active $\sim \mathrm{CHIC}(\mathrm{O}) \mathrm{OBu}$ chain ends. ${ }^{12}$ The polyacrylate synthesized by this synthetic method are telechelic $\alpha, \omega$-di(iodo)poly(butyl acrylates).

\section{Effect of Ratio of Reacted Monomer to Initiator}

The kinetics experiments described in this publication were carried out in a $50-\mathrm{mL}$ glass highpressure tube equipped with a magnetic stirring bar. Each point depicted in the kinetics plots represents a single experiment.

SET-DTLRP of BA was carried out in water media containing $\mathrm{NaHCO}_{3}$ as buffer and was catalyzed by $\mathrm{Na}_{2} \mathrm{~S}_{2} \mathrm{O}_{4}$. The initiator was iodoform that is a bifunctional initiator in $\mathrm{Na}_{2} \mathrm{~S}_{2} \mathrm{O}_{4}$ mediated SET-DTLRP. ${ }^{9}$ This system proved to be efficient for the polymerization of vinyl chloride, ${ }^{9}$ 2-ethylhexyl acrylate and tert-butyl acrylate $^{12}$ in water at room temperature. For that purpose, the $\mathrm{C}-\mathrm{I}$ bond should be labile enough to allow the transfer and the $\mathrm{R}$ (acrylate group) should stabilize the resulting radical through inductive and resonance effects. ${ }^{15}$ Additionally, in this particular system the activation results also from an electron transfer between the $\mathrm{SO}_{2}^{\bullet-}$ radical anion and the iodine containing compounds. However, this last possible reaction leads to an irreversible loss of active chain ends (eq 6).

The kinetics experiments shown in Figure 1 were obtained gravimetrically according to the procedure described (vide infra). 


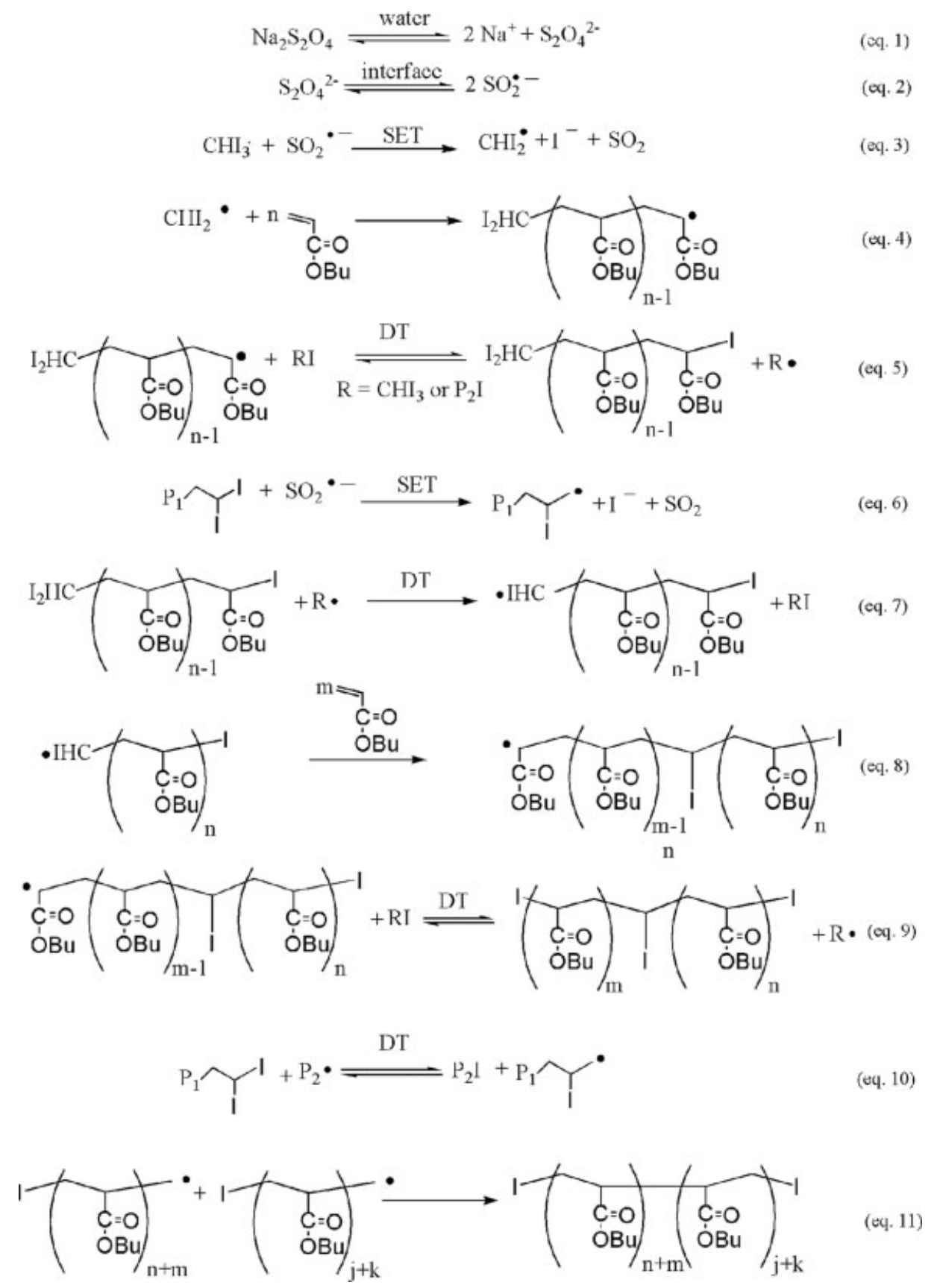

Scheme 1. Simplified mechanism of SET/DTLRP of BA.

Figure 1(a) shows the kinetic plots for $\mathrm{Na}_{2} \mathrm{~S}_{2} \mathrm{O}_{4} /$ $\mathrm{NaHCO}_{3}$-catalyzed LRP of BA prepared at $35{ }^{\circ} \mathrm{C}$ for the following conditions: $[\mathrm{BA}] /\left[\mathrm{CHI}_{3}\right] /\left[\mathrm{Na}_{2} \mathrm{~S}_{2} \mathrm{O}_{4}\right] /$ $\left[\mathrm{NaHCO}_{3}\right]=100 / 1 / 4 / 1.45(\mathrm{~mol} / \mathrm{mol} / \mathrm{mol} / \mathrm{mol})$; [MethocelF50V $[$ PVA 88$]=210 / 490(\mathrm{ppm} / \mathrm{ppm}, \mathrm{w} / \mathrm{w}$ relative to BA). The polymerization reached $87 \%$ conversion in just $2 \mathrm{~h}$ at $35{ }^{\circ} \mathrm{C}$ producing PBA with $M_{\mathrm{w}} / M_{\mathrm{n}}$ $=1.8$. This kinetics data exhibit two different slopes in $\ln [M]_{0} /[M]$ versus time. The first slope $k_{\mathrm{p} 1}=0.9024 \mathrm{~h}^{-1}$ represents the region diffusion of the monomer that is not limited by in the reaction mixture. The increase in conversion leads to a notorious enhancement of viscosity and formation of a solid phase, decreasing the polymerization rate. In a second stage, the kinetic constant $\left(k_{\mathrm{p} 2}\right)$ obtained is 56 times lower (0.0159) than $k_{\mathrm{p} 1}$. The described trend was also observed in the cases of SET-DTLRP of vinyl chloride, ${ }^{7-9,12}$ 2EHA and $t$-BA. ${ }^{12}$ The results demonstrate a first-order kinetic of the reaction 
a) $[\mathrm{BA}]_{0} /\left[\mathrm{CH}_{3}\right]_{0} /\left[\mathrm{Na}_{2} \mathrm{~S}_{2} \mathrm{O}_{4}\right]_{0} /\left[\mathrm{NaHCO}_{3}\right]_{0}=100 / 1 / 4 / 1.45$
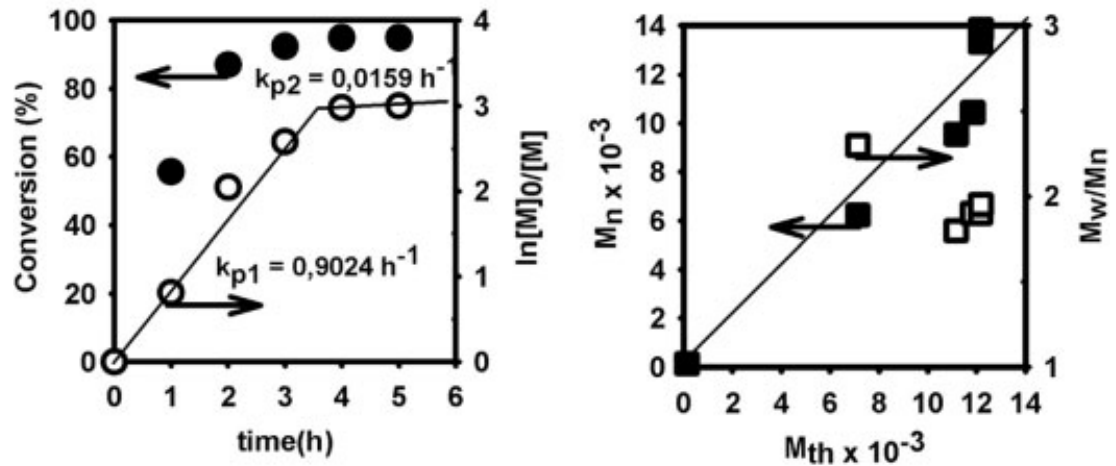

b) $[\mathrm{BA}]_{0} /\left[\mathrm{CH}_{3}\right]_{0} /\left[\mathrm{Na}_{2} \mathrm{~S}_{2} \mathrm{O}_{4}\right] 0 /\left[\mathrm{NaHCO}_{3}\right]_{0}=250 / 1 / 4 / 1.45$
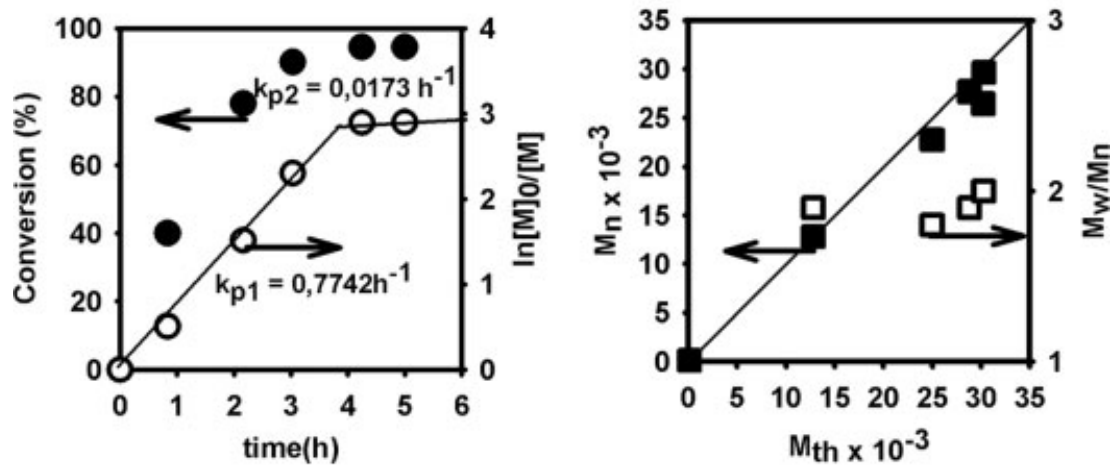

c) $\left.\left.[\mathrm{BA}]_{0} /\left[\mathrm{CH}_{3}\right]_{0} /\left[\mathrm{Na}_{2} \mathrm{~S}_{2} \mathrm{O}_{4}\right]\right]_{0} /\left[\mathrm{NaHCO}_{3}\right]\right]_{0}=400 / 1 / 4 / 1.45$
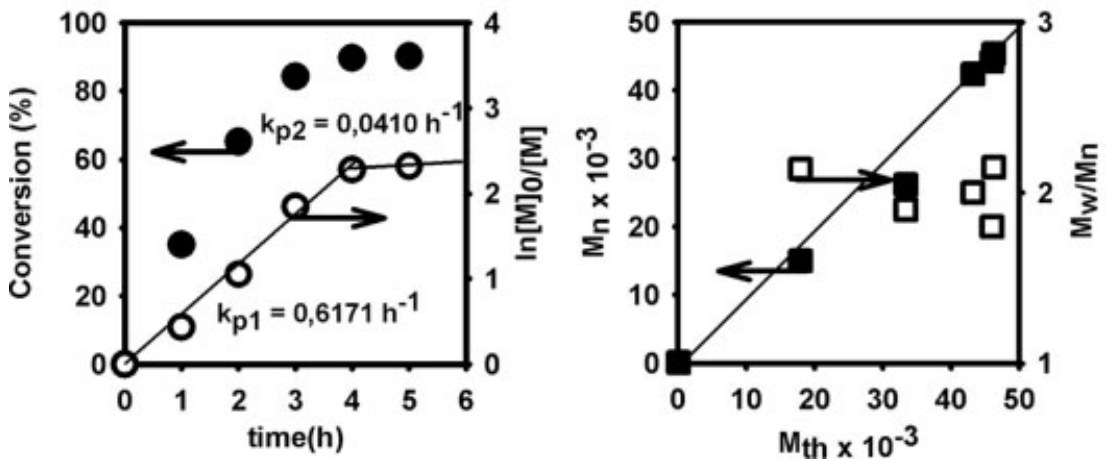

Figure 1. $\mathrm{Na}_{2} \mathrm{~S}_{2} \mathrm{O}_{4} / \mathrm{NaHCO}_{3}$-catalyzed $\mathrm{LRP}$ of $\mathrm{BA}$ initiated with iodoform in $\mathrm{H}_{2} \mathrm{O}$ in the presence of SA Methocel F50 and PVA 88, $[\mathrm{BA}]_{0} /\left[\mathrm{H}_{2} \mathrm{O}\right]_{0}=1 / 3(\mathrm{v} / \mathrm{v})$ : (a) $[\mathrm{BA}]_{0} /$ $\left[\mathrm{CHI}_{3}\right]_{0} /\left[\mathrm{Na}_{2} \mathrm{~S}_{2} \mathrm{O}_{4}\right]_{0} /\left[\mathrm{NaHCO}_{3}\right]_{0}=100 / 1 / 4 / 1.45(\mathrm{~mol} / \mathrm{mol} / \mathrm{mol} / \mathrm{mol}) ;[$ MethocelF50]/[PVA $88]=210 / 490(\mathrm{ppm} / \mathrm{ppm}, \mathrm{w} / \mathrm{w}$ relative to $\mathrm{BA}), 35{ }^{\circ} \mathrm{C}$; (b) $[\mathrm{BA}]_{0} /\left[\mathrm{CHI}_{3}\right]_{0} /\left[\mathrm{Na}_{2} \mathrm{~S}_{2} \mathrm{O}_{4}\right]_{0} /$ $\left[\mathrm{NaHCO}_{3}\right]_{0}=250 / 1 / 4 / 1.45(\mathrm{~mol} / \mathrm{mol} / \mathrm{mol} / \mathrm{mol}) ;[$ Methocel F50]/[PVA 88] $=210 / 490$ (ppm/ppm, w/w relative to BA), $35{ }^{\circ} \mathrm{C}$; (c) $[\mathrm{BA}]_{0} /\left[\mathrm{CHI}_{3}\right]_{0} /\left[\mathrm{Na}_{2} \mathrm{~S}_{2} \mathrm{O}_{4}\right]_{0} /\left[\mathrm{NaHCO}_{3}\right]_{0}=400 /$ $1 / 4 / 1.45(\mathrm{~mol} / \mathrm{mol} / \mathrm{mol} / \mathrm{mol})$; [Methocel F50]/[PVA 88] = 210/490 (ppm/ppm, w/w relative to BA), $35{ }^{\circ} \mathrm{C}$.

relatively to the concentration of monomer and a constant number of growing species through the polymerization process, therefore, the contribution of termination reactions might be neglected. This observation in addition to the linear dependence of $M_{\mathrm{n}, \mathrm{SEC}}$ versus theoretical molecular weight $\left(M_{\mathrm{n}}\right.$ th) supports the living polymerization mechanism. The initiation effi- 
a) $[\mathrm{BA}] 0 /\left[\mathrm{CHI}_{3}\right] 0 /\left[\mathrm{Na}_{2} \mathrm{~S}_{2} \mathrm{O}_{4}\right] 0 /\left[\mathrm{NaHCO}_{3}\right]_{0}=750 / 1 / 4 / 1.45$
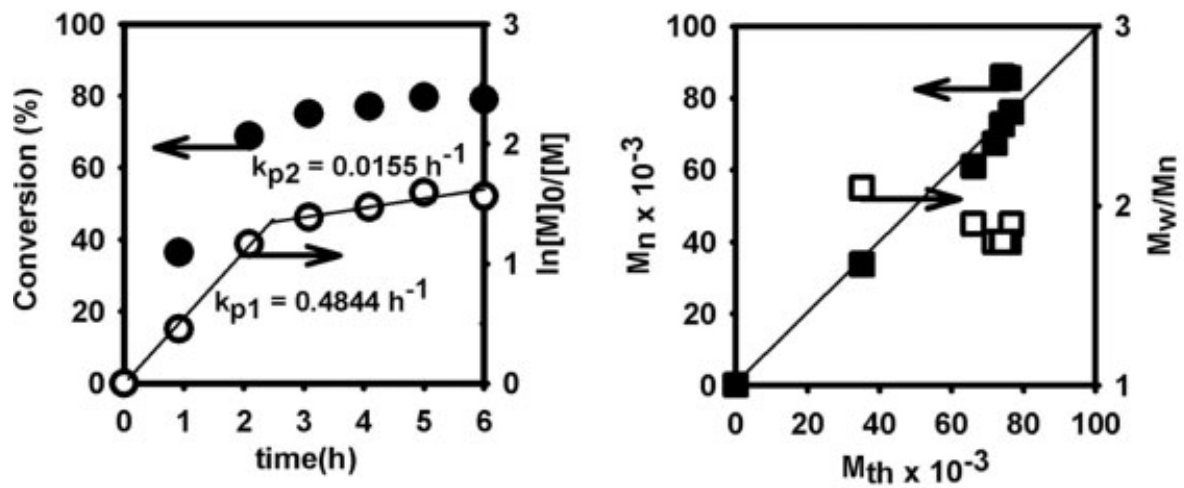

b) $\left.[\mathrm{BA}]_{0} /\left[\mathrm{CH}_{3}\right]_{0} /\left[\mathrm{Na}_{2} \mathrm{~S}_{2} \mathrm{O}_{4}\right]\right]_{0} /\left[\mathrm{NaHCO}_{3}\right]_{0}=1000 / 1 / 4 / 1.45$
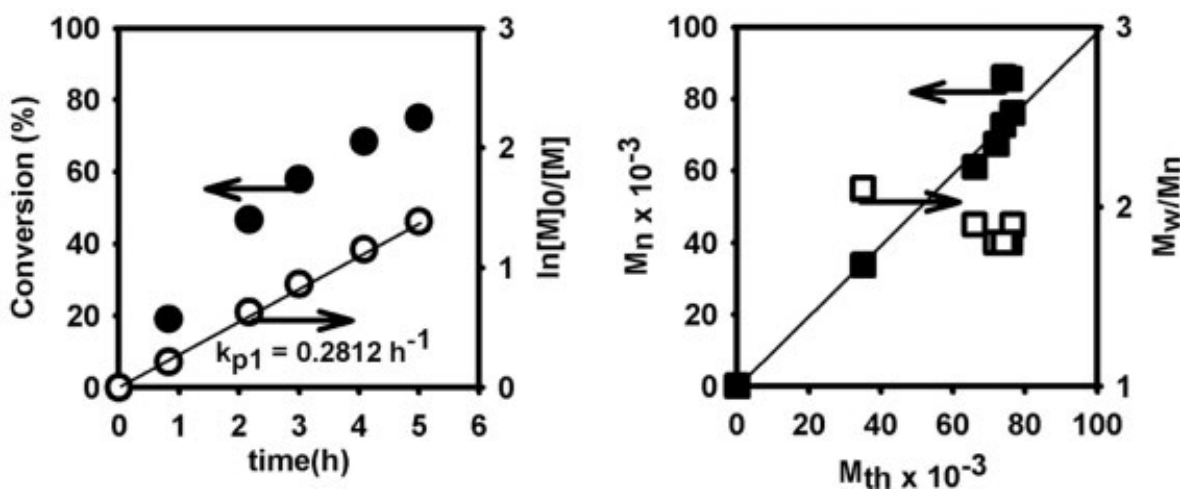

Figure 2. $\mathrm{Na}_{2} \mathrm{~S}_{2} \mathrm{O}_{4} / \mathrm{NaHCO}_{3}$-catalyzed LRP of BA initiated with iodoform in $\mathrm{H}_{2} \mathrm{O}$ in the presence of SA Methocel F50 and PVA 88, (a) $[\mathrm{BA}]_{0} /\left[\mathrm{CHI}_{3}\right]_{0} /\left[\mathrm{Na}_{2} \mathrm{~S}_{2} \mathrm{O}_{4}\right]_{0} /$ $\left[\mathrm{NaHCO}_{3}\right]_{0}=750 / 1 / 4 / 1.45(\mathrm{~mol} / \mathrm{mol} / \mathrm{mol} / \mathrm{mol}) ;[$ Methocel F50]/[PVA 88] $=210 / 490$ $\left(\mathrm{ppm} / \mathrm{ppm}\right.$, w/w relative to BA), $35{ }^{\circ} \mathrm{C}$; (b) $[\mathrm{BA}]_{0} /\left[\mathrm{CHI}_{3}\right]_{0} /\left[\mathrm{Na}_{2} \mathrm{~S}_{2} \mathrm{O}_{4}\right]_{0} /\left[\mathrm{NaHCO}_{3}\right]_{0}$ $=1000 / 1 / 4 / 1.45(\mathrm{~mol} / \mathrm{mol} / \mathrm{mol} / \mathrm{mol}) ;$ [Methocel F50]/[PVA 88] $=210 / 490(\mathrm{ppm} / \mathrm{ppm}, \mathrm{w} / \mathrm{w}$ relative to BA), $35{ }^{\circ} \mathrm{C}$.

ciency $\left(I_{\text {ef }}\right)$ that relates the $M_{\mathrm{n}, \mathrm{SEC}}$ and $M_{n}$ th, for this polymerization was 0.96 . Thus, two important aspects must be referred. First, the reaction mechanism at the considered temperature $\left(35{ }^{\circ} \mathrm{C}\right)$ proceeds as expected. Secondly, the good agreement between $M_{\mathrm{n}}$ th and $M_{\mathrm{n}, \mathrm{SEC}}$ values most probably could only be achieved because of utilization of a SEC multidetector equipment that determines the exact molecular weight using a combination of three detectors. The precision of the TriSEC equipments have been proved in several works published in literature. ${ }^{16-18}$ The utilization of a multidetector enables us to determine absolute molecular weights with high precision, and is less sensitive to errors that normally occur in conventional SEC with RI detectors, as the change in the eluent flow. ${ }^{19}$ The necessity of using the universal calibration per- formed with commercial standards is by this way avoided.

As reported in literature, ${ }^{12}$ the ratio $M_{\mathrm{w}} / M_{\mathrm{n}}$ obtained for SET-DTLRP reactions is around 2.0. The high polydispersity obtained for the PBA when compared to the theoretical one that could be expected for a living polymerization can be ascribed to the heterogeneity of the medium. Moreover, for a typical solution LRP system, the decrease in the value of $M_{\mathrm{wi}} / M_{\mathrm{n}}$ with the monomer conversion can be observed. Effectively, after the first hour of reaction it is possible to observe a decrease of $M_{\mathrm{w}} / M_{\mathrm{n}}$ for all the ratios $[\mathrm{BA}]_{0} /\left[\mathrm{CHI}_{3}\right]_{0}$ studied. This trend is valid to the region between the first hour and the break point. Then, for higher reaction times due to the system heterogeneity $M_{\mathrm{w}} / M_{\mathrm{n}}$ remains constant or slightly increases. Another theoretical 
Table 1. SET-DTLRP of PBA for Different $M_{\mathrm{n}}$ th Targets Under the Following Conditions: $[\mathrm{BA}]_{0} /\left[\mathrm{CHI}_{3}\right]_{0} /\left[\mathrm{Na}_{2} \mathrm{~S}_{2} \mathrm{O}_{4}\right]_{0} /\left[\mathrm{NaHCO}_{3}\right]_{0}=\mathrm{DP} / 1 / 4 / 1.45(\mathrm{~mol} / \mathrm{mol} / \mathrm{mol} / \mathrm{mol})$; $[$ MethocelF50]/[PVA 88] $=210 / 490(\mathrm{ppm} / \mathrm{ppm}$. w/w relative to BA $)$

\begin{tabular}{cccccc}
\hline No. & $\mathrm{DP}[\mathrm{BA}]_{0} /[\mathrm{CHI} 3]_{0}$ & $\begin{array}{c}\text { Conversion at } \\
\text { breakpoint }(\%)\end{array}$ & $k_{\mathrm{p} 1}\left(\mathrm{~h}^{-1}\right)$ & $k_{\mathrm{p} 2}\left(\mathrm{~h}^{-1}\right)$ & $\begin{array}{c}M_{\mathrm{n}} \mathrm{th} \\
\left(10^{-3} \mathrm{Da}\right)\end{array}$ \\
\hline 1 & 100 & 92 & 0.9024 & 0.0159 & 12.817 \\
2 & 250 & 87 & 0.7742 & 0.0173 & 32,042 \\
3 & 400 & 84 & 0.6171 & 0.0410 & 51,268 \\
4 & 750 & 75 & 0.4844 & 0.0155 & 96,120 \\
5 & 1000 & 68 & 0.2812 & - & 128,170 \\
\hline
\end{tabular}

reason can be ascribed to the differences between the rate of exchange of iodine to the propagation radical and the rate of propagation, although considering the behavior described between the first hour and the breakpoint, this suggestion can be excluded for specific system.

Figures $1(b, c)$ and $2(a, b)$ illustrate the kinetics obtained for the same conditions but for different molecular weight targets. It can be observed that the same curve tendency is described before, although with different polymerization rates. In all cases, the theoretical molecular weight predicted by the initial ratio [monomer]/[initiator]

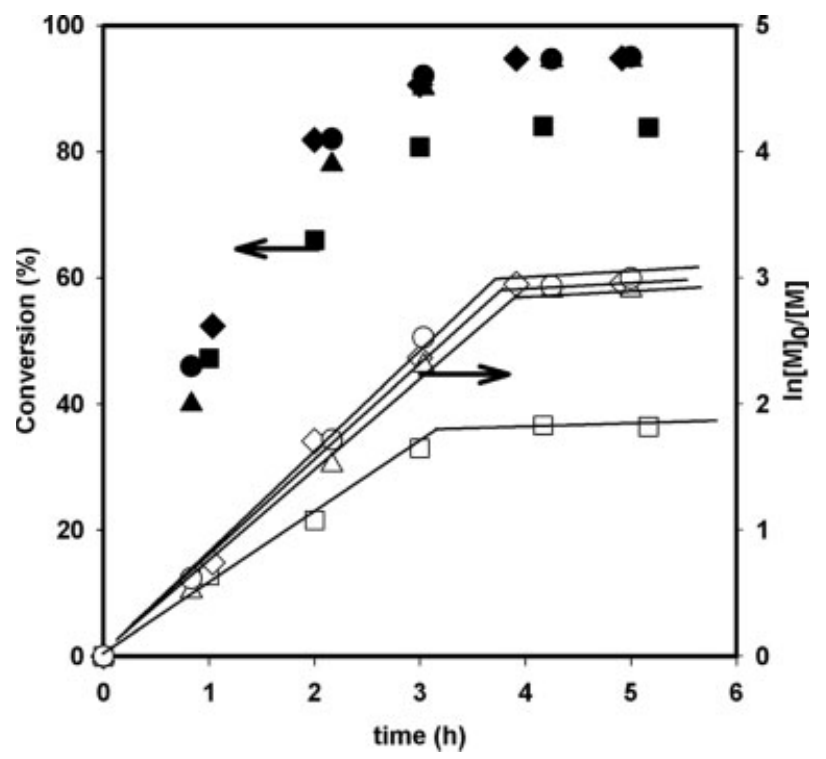

Figure 3. $\mathrm{Na}_{2} \mathrm{~S}_{2} \mathrm{O}_{4} / \mathrm{NaHCO}_{3}$-catalyzed LRP of $\mathrm{BA}$ initiated with iodoform in $\mathrm{H}_{2} \mathrm{O}$ in the presence of SA Methocel F50 and PVA 88, $[\mathrm{BA}]_{0} /\left[\mathrm{H}_{2} \mathrm{O}\right]_{0}=1 / 3(\mathrm{v} / \mathrm{v}):[\mathrm{BA}]_{0} /\left[\mathrm{CHI}_{3}\right]_{0} /$ $\left[\mathrm{Na}_{2} \mathrm{~S}_{2} \mathrm{O}_{4}\right]_{0} /\left[\mathrm{NaHCO}_{3}\right]_{0}=250 / 1 /\left[\mathrm{Na}_{2} \mathrm{~S}_{2} \mathrm{O}_{4}\right]_{0} / 1.45(\mathrm{~mol} / \mathrm{mol} /$ $\mathrm{mol} / \mathrm{mol}) ;$ [MethocelF50]/[PVA 88] $=210 / 490(\mathrm{ppm} / \mathrm{ppm}$, $\mathrm{w} / \mathrm{w}$ relative to $\mathrm{BA}), 35{ }^{\circ} \mathrm{C}$; (回) $\left[\mathrm{Na}_{2} \mathrm{~S}_{2} \mathrm{O}_{4}\right]=1$; ( $\left[\mathrm{Na}_{2} \mathrm{~S}_{2} \mathrm{O}_{4}\right]=2 ;(\boldsymbol{\Delta})\left[\mathrm{Na}_{2} \mathrm{~S}_{2} \mathrm{O}_{4}\right]=4 ;(\mathbf{O})\left[\mathrm{Na}_{2} \mathrm{~S}_{2} \mathrm{O}_{4}\right]=8$. matches with molecular weight determined by TriSEC. Table 1 shows the comparison between the polymerization rates obtained for the different molecular weight targets.

Table 1 shows that the rate of polymerization clearly decreases with the increase in ratio [BA]/ $\left[\mathrm{CHI}_{3}\right]$. Furthermore, the acrylates do not display an autopolymerization mechanism that can generate new radicals, ${ }^{6}$ especially at $35{ }^{\circ} \mathrm{C}$, which may undergo chain transfer reactions with the iodine chain ends increasing the rate of polymerization in the beginning. It can be observed that the conversion decreases as the target molecular weight increases. The existence of a break point in the polymerization kinetics is also typically observed for polymerizations under starvefeed conditions. In those cases, its presence is ascribed to the high internal viscosity of the particles leading to important reduction of bimolecular exchange between the active molecules and the dormant species, which is essential to guarantee a good control over the process. ${ }^{20}$

\section{Effect of the Amount of $\mathrm{Na}_{2} \mathrm{~S}_{2} \mathrm{O}_{4}$}

The dependence of the rate of polymerization on the $\mathrm{Na}_{2} \mathrm{~S}_{2} \mathrm{O}_{4}$ concentration is presented in Figure 3 and summarized in Table 2. The kinetics studies were carried out for the follow-

Table 2. Rate Constants Obtained for Different Ratios $\left[\mathrm{Na}_{2} \mathrm{~S}_{2} \mathrm{O}_{4}\right]_{0} /\left[\mathrm{CHI}_{3}\right]_{0}$

\begin{tabular}{cccc}
\hline No. & {$\left[\mathrm{Na}_{2} \mathrm{~S}_{2} \mathrm{O}_{4}\right]_{0} /\left[\mathrm{CHI}_{3}\right]_{0}$} & $k_{\mathrm{p} 1}\left(\mathrm{~h}^{-1}\right)$ & $k_{\mathrm{p} 2}\left(\mathrm{~h}^{-1}\right)$ \\
\hline 1 & $1: 1$ & 0.5528 & 0.0815 \\
2 & $2: 1$ & 0.7673 & 0.0025 \\
3 & $4: 1$ & 0.7776 & 0.0173 \\
4 & $8: 1$ & 0.7821 & 0.0265 \\
\hline
\end{tabular}

Journal of Polymer Science: Part A: Polymer Chemistry DOI 10.1002/pola 


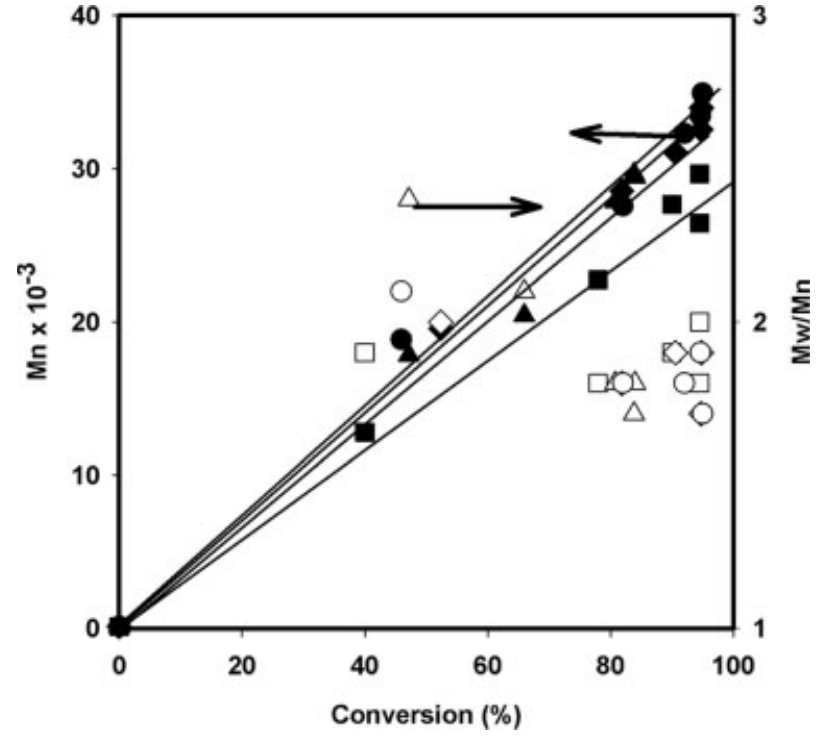

Figure 4. Dependence of molecular weights and polydispersity on conversion for the $\mathrm{Na}_{2} \mathrm{~S}_{2} \mathrm{O}_{4} / \mathrm{NaHCO}_{3}$-catalyzed LRP of BA initiated with iodoform in $\mathrm{H}_{2} \mathrm{O}$ in the presence of SA Methocel F50 and PVA 88 for the following conditions: $[\mathrm{BA}]_{0} /\left[\mathrm{H}_{2} \mathrm{O}\right]_{0}=1 / 3(\mathrm{v} / \mathrm{v}):[\mathrm{BA}]_{0} /$ $\left[\mathrm{CHI}_{3}\right]_{0} /\left[\mathrm{Na}_{2} \mathrm{~S}_{2} \mathrm{O}_{4}\right]_{0} /\left[\mathrm{NaHCO}_{3}\right]_{0}=250 / 1 /\left[\mathrm{Na}_{2} \mathrm{~S}_{2} \mathrm{O}_{4}\right]_{0} / 1.45$ $(\mathrm{mol} / \mathrm{mol} / \mathrm{mol} / \mathrm{mol}) ;[$ MethocelF50]/[PVA 88] $=210 / 490$ (ppm/ppm, w/w relative to $\mathrm{BA}), 35{ }^{\circ} \mathrm{C}$; ( $\mathbf{( \square )}\left[\mathrm{Na}_{2} \mathrm{~S}_{2} \mathrm{O}_{4}\right]$ $=1 ;(\diamond)\left[\mathrm{Na}_{2} \mathrm{~S}_{2} \mathrm{O}_{4}\right]=2 ;(\mathbf{\Lambda})\left[\mathrm{Na}_{2} \mathrm{~S}_{2} \mathrm{O}_{4 \mathrm{t}}\right]=4 ;(\boldsymbol{\bullet})$ $\left[\mathrm{Na}_{2} \mathrm{~S}_{2} \mathrm{O}_{4}\right]=8$.

ing conditions: $[\mathrm{BA}]_{0} /\left[\mathrm{CHI}_{3}\right]_{0} /\left[\mathrm{Na}_{2} \mathrm{~S}_{2} \mathrm{O}_{4}\right]_{0} /\left[\mathrm{NaHCO}_{3}\right]_{0}$ $=250 / 1 /\left[\mathrm{Na}_{2} \mathrm{~S}_{2} \mathrm{O}_{4}\right]_{0} / 1.45(\mathrm{~mol} / \mathrm{mol} / \mathrm{mol} / \mathrm{mol}) ;$ [MethocelF50]/[PVA 88$]=210 / 490(\mathrm{ppm} / \mathrm{ppm}, \mathrm{w} / \mathrm{w}$ relative to BA), $35{ }^{\circ} \mathrm{C}$.

The results presented in Table 2 suggest that the dependence of the SET-DTLRP kinetics with respect to $\mathrm{Na}_{2} \mathrm{~S}_{2} \mathrm{O}_{4}$ is not linear. Those results indicate that there is an optimum amount of $\mathrm{Na}_{2} \mathrm{~S}_{2} \mathrm{O}_{4}$ to be used. After a certain level of catalyst concentration, the polymerization rate remains almost constant. The main reason behind this result is not fully understood. However, it may be related to the mechanism involved in the diffusion of radical anion $\mathrm{SO}_{2} \bullet$ species through the monomer phase (eq 2). This diffusional process is controlled by the equilibrium of sulfur species between the organic and aqueous phase, and for that reason is not directly dependent on the amount of $\mathrm{Na}_{2} \mathrm{~S}_{2} \mathrm{O}_{4}$ presented in the water phase. Without the equilibrium mechanism of $\mathrm{Na}_{2} \mathrm{~S}_{2} \mathrm{O}_{4}$, it could be expected for high ratios $\left[\mathrm{Na}_{2} \mathrm{~S}_{2} \mathrm{O}_{4}\right]_{0} /\left[\mathrm{CHI}_{3}\right]_{0}$ a very high radical concentration in the very beginning of the reaction. This could originate two different situations: the end of reaction at very

Journal of Polymer Science: Part A: Polymer Chemistry DOI 10.1002/pola low conversion due to recombination between the radicals; or the formation of polymer chains with much higher molecular weight than expected due to consumption of iodine (eq 6) that eventually could produce an uncontrolled reaction. The difference between the rate of polymerization obtained for $\left[\mathrm{Na}_{2} \mathrm{~S}_{2} \mathrm{O}_{4}\right]_{0} /\left[\mathrm{CHI}_{3}\right]_{0}$ $=1$ and $\left[\mathrm{Na}_{2} \mathrm{~S}_{2} \mathrm{O}_{4}\right]_{0} /\left[\mathrm{CHI}_{3}\right]_{0}=2$ might be related to the role of this compound in the oxygen consumption. ${ }^{9}$ In contrast to other homogeneous LRP systems, the rate of polymerization of this heterogeneous system appears to be almost independent of the catalyst concentration after a certain level. For the specific polymerization degree used here $(\mathrm{DP}=250)$ at $35{ }^{\circ} \mathrm{C}$, the ideal ratio $\left[\mathrm{Na}_{2} \mathrm{~S}_{2} \mathrm{O}_{4}\right]_{0} /\left[\mathrm{CHI}_{3}\right]_{0}$ appears to be close to 2, although for other DP's this ratio may be different taking into account the influence of other parameters.

Figure 4 shows the linear increase of molecular weight with the conversion regardless the amount of sodium dithionate used in the polymerization. It is proved by this means that the controlled mechanism remains for the different proportion of $\mathrm{Na}_{2} \mathrm{~S}_{2} \mathrm{O}_{4}$ studied. This behavior constitutes an additional proof relatively to the existence of the equilibrium that control the dif-

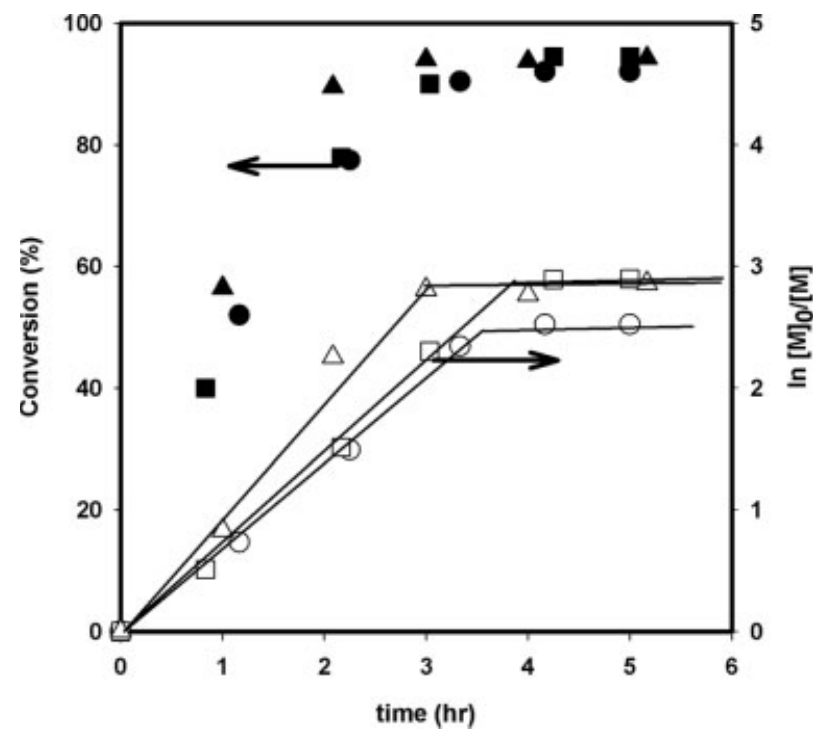

Figure 5. $\mathrm{Na}_{2} \mathrm{~S}_{2} \mathrm{O}_{4} / \mathrm{NaHCO}_{3}$-catalyzed LRP of BA initiated with iodoform in $\mathrm{H}_{2} \mathrm{O}$ in the presence of SA Methocel F50 and PVA 88, $[\mathrm{BA}] /\left[\mathrm{H}_{2} \mathrm{O}\right]=1 / 3(\mathrm{v} / \mathrm{v})$ : $[\mathrm{BA}]_{0} /\left[\mathrm{CHI}_{3}\right]_{0} /\left[\mathrm{Na}_{2} \mathrm{~S}_{2} \mathrm{O}_{4}\right]_{0} /\left[\mathrm{NaHCO}_{3}\right]_{0}=250 / 1 / 4 / 1.45$ $(\mathrm{mol} / \mathrm{mol} / \mathrm{mol} / \mathrm{mol})$ at $35{ }^{\circ} \mathrm{C}$ : (O) [Methocel F50]/[PVA $88]=210 / 490 ;(\mathbf{\square})[$ Methocel F50]/[PVA 88] = 420/980; (A) $[$ Methocel F50]/[PVA 88] = 840/1960 $(\mathrm{ppm} / \mathrm{ppm}$, $\mathrm{w} / \mathrm{w}$ relative to $\mathrm{BA})$. 


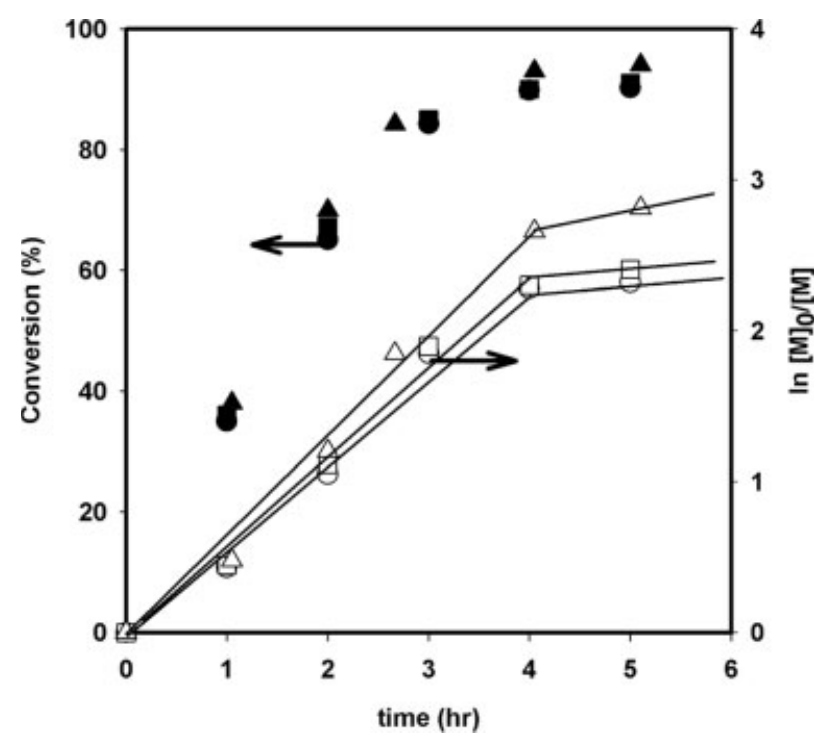

Figure 6. $\mathrm{Na}_{2} \mathrm{~S}_{2} \mathrm{O}_{4} / \mathrm{NaHCO}_{3}$-catalyzed LRP of BA initiated with iodoform in $\mathrm{H}_{2} \mathrm{O}$ in the presence of $\mathrm{SA}$ Methocel F50 and PVA 88, $[\mathrm{BA}]_{0}\left[\left[\mathrm{H}_{2} \mathrm{O}\right]_{0}=1 / 3(\mathrm{v} / \mathrm{v})\right.$ : $[\mathrm{BA}]_{0} /\left[\mathrm{CHI}_{3}\right]_{0} /\left[\mathrm{Na}_{2} \mathrm{~S}_{2} \mathrm{O}_{4}\right]_{0} /\left[\mathrm{NaHCO}_{3}\right]_{0}=400 / 1 / 4 / 1.45(\mathrm{~mol} /$ $\mathrm{mol} / \mathrm{mol} / \mathrm{mol}$ ) at $35{ }^{\circ} \mathrm{C}$ : (O) [Methocel F50]/[PVA 88]

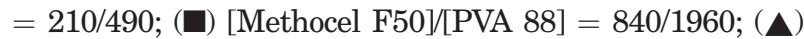
[Methocel F50]/[PVA 88] $=1680 / 3920(\mathrm{ppm} / \mathrm{ppm}, \mathrm{w} / \mathrm{w}$ relative to $\mathrm{BA}$ ).

fusion of the sulfur compounds from the water to the organic phase (BA).

\section{Amount of Suspending Agent}

The effect of the amount of suspending agent in the reaction rate was studied for the following conditions: $[\mathrm{BA}]_{0} /\left[\mathrm{CHI}_{3}\right]_{0} /\left[\mathrm{Na}_{2} \mathrm{~S}_{2} \mathrm{O}_{4}\right]_{0} /\left[\mathrm{NaHCO}_{3}\right]_{0}$ $=250 / 1 / 4 / 1.45(\mathrm{~mol} / \mathrm{mol} / \mathrm{mol} / \mathrm{mol}) ;$ for different ratios $[\mathrm{MF} 50] /[\mathrm{PVA} 88](\mathrm{ppm} / \mathrm{ppm}, \mathrm{w} / \mathrm{w}$ relative to BA) at $35{ }^{\circ} \mathrm{C}$, and it is shown in Figure 5 .

Figure 5 shows the evolution of the conversion and $\ln [M]_{0} /[M]$ with the reaction time for a ratio $[\mathrm{BA}]_{0} /\left[\mathrm{CHI}_{3}\right]_{0}$ of 250 . The dependence of the rate of polymerization on the suspending agent content is only detected for higher of 2800 ppm (840 ppm MF50 + 1960 ppm PVA).

Although, when the same study was carried out for the ratio $[\mathrm{BA}]_{0} /\left[\mathrm{CHI}_{3}\right]_{0}$ of 400 (Fig. 6), the results show that the difference is only observed for even higher values of suspending agent.

According to the results obtained for the amount of suspension agents, higher levels of these compounds lead to the enhancement of the polymerization rate. However, as the ratio $[\mathrm{BA}]_{0} /\left[\mathrm{CHI}_{3}\right]_{0}$ increases the necessity of suspend- ing agents to increase the rate of polymerization is also higher. These results suggest that as the molecular weight increases, the amount of suspending need to stabilize the suspension should also increase. For high concentration of suspending agents, the biggest difference was achieved in the second part of the polymerization, after the breakpoint.

\section{Effect of Temperature}

The effect of temperature on the SET-DTLRP of butyl acrylate (Figs. 7 and 8) was studied for the following conditions: $[\mathrm{BA}]_{0} /\left[\mathrm{CHI}_{3}\right]_{0} /\left[\mathrm{Na}_{2} \mathrm{~S}_{2} \mathrm{O}_{4}\right]_{0} /$ $\left[\mathrm{NaHCO}_{3}\right]_{0}=25 / 1 / 4 / 1.45(\mathrm{~mol} / \mathrm{mol} / \mathrm{mol} / \mathrm{mol}) ;[\mathrm{MF} 50] /$ [PVA 88] $=420 / 980(\mathrm{ppm} / \mathrm{ppm}, \mathrm{w} / \mathrm{w}$ relative to BA). It is known that for certain DT-LRP polymerizations, high reactions temperatures should be avoid due to the possibility of decomposition of the chain end of iodo-terminated polymers, ${ }^{15}$ leading to uncontrolled processes. The main target here was to determine the highest temperature possible to keep the controlled/"living" character of this polymerization.

As expected, the polymerization rate increases with the temperature. The $\ln [M]_{0} /[M]$ versus time is linear, indicating a controlled process, and the theoretical molecular weight matches well with the obtained molecular weight for reaction temperatures until $45{ }^{\circ} \mathrm{C}$.

The plots of $M_{\text {th }}$ versus $M_{\mathrm{n}}$ shown in Figure 6 proved that until $45{ }^{\circ} \mathrm{C}$, no dimerization occurred because of the monomer starvation (usually after 2 or $3 \mathrm{~h}$ ). Although for $60{ }^{\circ} \mathrm{C}$ such differences are much higher and significant, showing that the living feature of the reaction was lost probably because of the iodine consumption.

Previous studies carried out with the TriSEC equipment ${ }^{21}$ have shown that the RALLS and the DV are extremely sensitive detectors. In this specific case, since the molecular weight target studied and the $\mathrm{d} n / \mathrm{d} c$ are very low ([BA $]_{0} /$ $\left[\mathrm{CHI}_{3}\right]_{0}=25$ and $\mathrm{d} n / \mathrm{d} c$ around 0.0651 ), the ratio signal/noise is higher for the DV chromatogram. Figure 9 presents the DV chromatogram of four samples prepared with the same conditions presented in Figure 6 but for $5 \mathrm{~h}$ of reaction.

From Figure 9, it can be concluded that only at $25{ }^{\circ} \mathrm{C}$ no shoulder is detected in the DV chromatogram. For 35 and $45{ }^{\circ} \mathrm{C}$ a very slight shoulder appears but can be ignored. Moreover, the results show that until $45{ }^{\circ} \mathrm{C}$ the elution peak is obtained for the same volume. For the temperature $60{ }^{\circ} \mathrm{C}$, a bimodal distribution of mo- 
a) $\left.[\mathrm{BA}] 0 /\left[\mathrm{CH}_{3}\right]_{0} /\left[\mathrm{Na}_{2} \mathrm{~S}_{2} \mathrm{O}_{4}\right]\right]_{0} /\left[\mathrm{NaHCO}_{3}\right]_{0}=25 / 1 / 4 / 1.45,25^{\circ} \mathrm{C}$
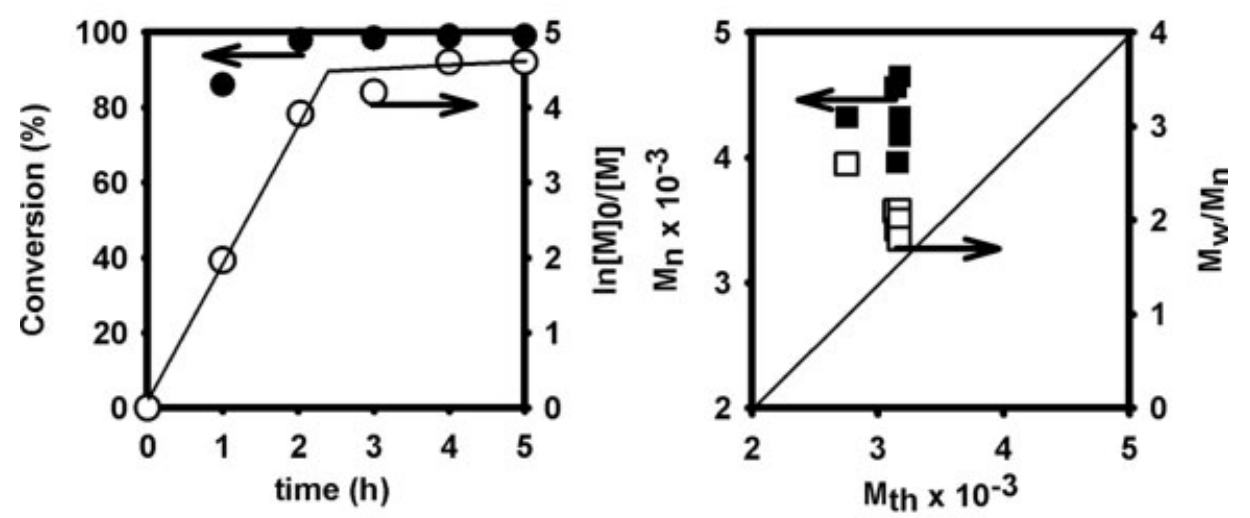

b) $[\mathrm{BA}]_{0} /\left[\mathrm{CH}_{3}\right]_{0} /\left[\mathrm{Na}_{2} \mathrm{~S}_{2} \mathrm{O}_{4}\right]_{0} /\left[\mathrm{NaHCO}_{3}\right]_{0}=25 / 1 / 4 / 1.45,35^{\circ} \mathrm{C}$
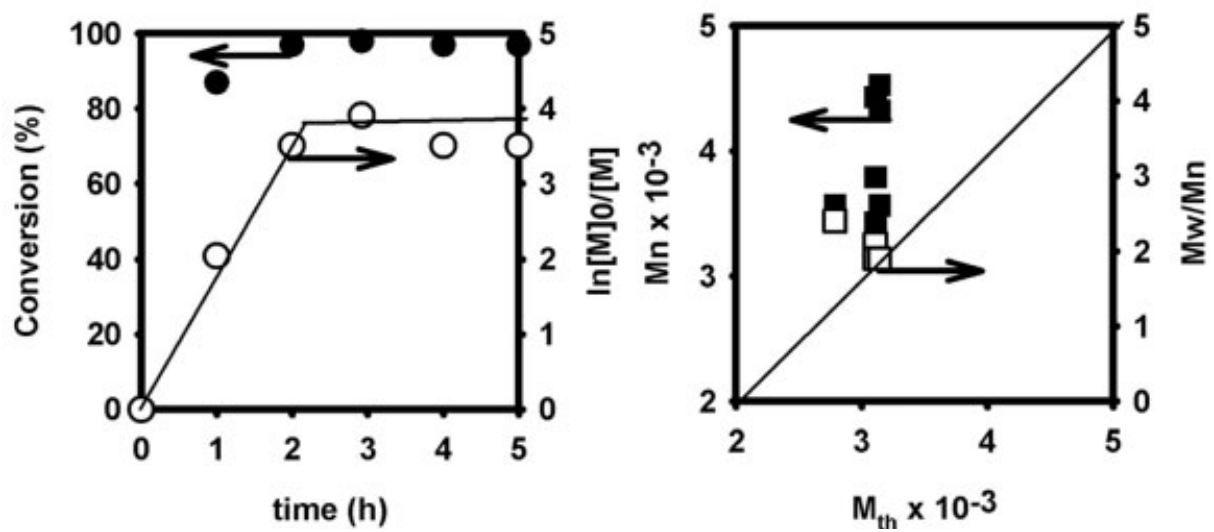

Figure 7. $\mathrm{Na}_{2} \mathrm{~S}_{2} \mathrm{O}_{4} / \mathrm{NaHCO}_{3}$-catalyzed $\mathrm{LRP}$ of $\mathrm{BA}$ initiated with iodoform in $\mathrm{H}_{2} \mathrm{O}$ in the presence of SA Methocel F50 and PVA 88, $[\mathrm{BA}]_{0} /\left[\mathrm{H}_{2} \mathrm{O}\right]_{0}=1 / 3(\mathrm{v} / \mathrm{v})$ for the following conditions: $[\mathrm{BA}]_{0} /\left[\mathrm{CHI}_{3}\right]_{0} /\left[\mathrm{Na}_{2} \mathrm{~S}_{2} \mathrm{O}_{4}\right]_{0} /\left[\mathrm{NaHCO}_{3}\right]_{0}=25 / 1 / 4 / 1.45(\mathrm{~mol} / \mathrm{mol} / \mathrm{mol} / \mathrm{mol})$; $\left[\right.$ Methocel F50]/[PVA 88] $=420 / 980\left(\mathrm{ppm} / \mathrm{ppm}\right.$, w/w relative to BA), (a) $25{ }^{\circ} \mathrm{C}$, (b) $35{ }^{\circ} \mathrm{C}$.

lecular weight is detected that suggests two different mechanisms in the reaction medium: the free radical polymerization that results from the high level of iodine consumption and the living radical polymerization fraction that occur in the chains that could retain the iodine for longer time. This deviation from the normal molecular weight distribution presented obtained for $60{ }^{\circ} \mathrm{C}$ can result from two different reasons. First, it may be ascribed to radical dimerization that results from high radical concentration produced by the high temperature used. Secondly, it might result from the consumption of iodine (eq 6) due to the high temperature considered (e.g., a possible two-electron reduction of $\sim \mathrm{C}-\mathrm{I}$ at elevated temperature). ${ }^{22}$

The broadening of the molecular weight distributions can result from reversible termination reactions. For monomers such as the BA that possesses a high propagation rate constant, even when living radical polymerization is achieved the broadening may be observed and does not mean the loss of livingness. ${ }^{20}$

The results show that it is possible to obtain very low molecular weight PBA without changing the procedure used for temperature lower than $45{ }^{\circ} \mathrm{C}$, since the molecular weight obtained by SEC is similar to the theoretical one. For very high concentrations of initiator, the presence of relatively high concentration of radicals at the early stages of the polymerization could be expected, even for low polymerization temperatures. This situation would unavoidably lead to some recombination of the growing radicals, conducting to the formation of polymers with higher $M_{\mathrm{n}}$ than expected. 
a) $\left.[\mathrm{BA}]_{0} /\left[\mathrm{CHI}_{3}\right]_{0} /\left[\mathrm{Na}_{2} \mathrm{~S}_{2} \mathrm{O}_{4}\right]\right]_{0} /\left[\mathrm{NaHCO}_{3}\right]_{0}=25 / 1 / 4 / 1.45,45^{\circ} \mathrm{C}$
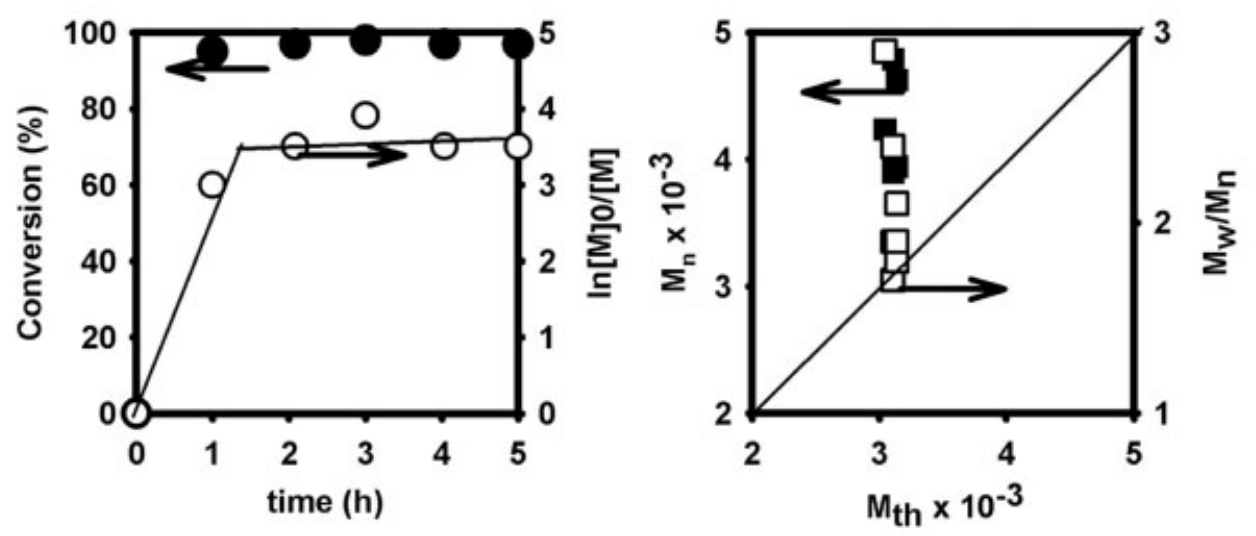

b) $[\mathrm{BA}]_{0} /\left[\mathrm{CHI}_{3}\right]_{0} /\left[\mathrm{Na}_{2} \mathrm{~S}_{2} \mathrm{O}_{4}\right]_{0} /\left[\mathrm{NaHCO}_{3}\right]_{0}=25 / 1 / 4 / 1.45,60^{\circ} \mathrm{C}$
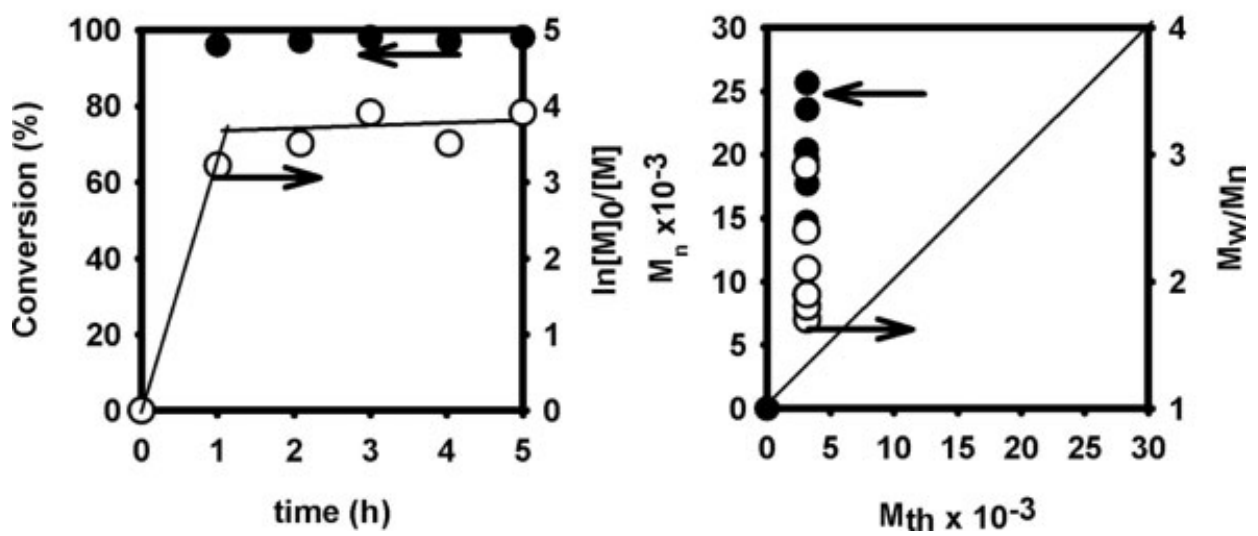

Figure 8. $\mathrm{Na}_{2} \mathrm{~S}_{2} \mathrm{O}_{4} / \mathrm{NaHCO}_{3}$-catalyzed LRP of BA initiated with iodoform in $\mathrm{H}_{2} \mathrm{O}$ in the presence of SA Methocel F50 and PVA 88, $[\mathrm{BA}]_{0} /\left[\mathrm{H}_{2} \mathrm{O}\right]_{0}=1 / 3(\mathrm{v} / \mathrm{v})$ for the following conditions: $[\mathrm{BA}]_{0} /\left[\mathrm{CHI}_{3}\right]_{0} /\left[\mathrm{Na}_{2} \mathrm{~S}_{2} \mathrm{O}_{4}\right]_{0} /\left[\mathrm{NaHCO}_{3}\right]_{0}=25 / 1 / 4 / 1.45(\mathrm{~mol} / \mathrm{mol} / \mathrm{mol} / \mathrm{mol})$; [Methocel F50]/[PVA 88] = 420/980 $\left(\mathrm{ppm} / \mathrm{ppm}\right.$, w/w relative to BA), (a) $45{ }^{\circ} \mathrm{C}$, (b) $60{ }^{\circ} \mathrm{C}$.

The kinetics for a $\mathrm{DP}=250$ were carried out at 35 and $60{ }^{\circ} \mathrm{C}$, under the following conditions: $[\mathrm{BA}]_{0} /\left[\mathrm{CHI}_{3}\right]_{0} /\left[\mathrm{Na}_{2} \mathrm{~S}_{2} \mathrm{O}_{4}\right]_{0} /\left[\mathrm{NaHCO}_{3}\right]_{0}=250 / 1 / 4 /$ $1.45(\mathrm{~mol} / \mathrm{mol} / \mathrm{mol} / \mathrm{mol}) ;[\mathrm{MF} 50] /[\mathrm{PVA} 88]=420 /$ $980(\mathrm{ppm} / \mathrm{ppm}, \mathrm{w} / \mathrm{w}$ relative to $\mathrm{BA})$.

Figure 10 shows a similar behavior, the dependence of conversion and $\ln [M]_{0} /[M]$ with the reaction time, regardless the reaction temperature.

The linear increase of $M_{\mathrm{n}, \mathrm{SEC}}$ and Rg with the conversion (Fig. 11) is only obtained at $35{ }^{\circ} \mathrm{C}$. At polymerization temperature $60{ }^{\circ} \mathrm{C}$, the molecular weight determined by TriSEC does not match the theoretical molecular weight. Furthermore, the typical values obtained for $\mathrm{Rg}$ are much higher than expected. Based on these results, it can be stated that the controlled/living mechanism is not possible to achieve, even at $60{ }^{\circ} \mathrm{C}$ temperature for medium molecular weights.

From Figure 12, it is possible to observe that only at $35{ }^{\circ} \mathrm{C}$ the $M_{\mathrm{n}}$ th matches the $M_{\mathrm{n}, \mathrm{SEC}}$ determined by TriSEC.

In Figure 13, it is shown the evolution of the chromatogram shape for the SET-DTLRP of PBA at 35 and $60^{\circ} \mathrm{C}$. Both chromatograms were obtained for the two polymerization temperatures after 1 and $5 \mathrm{~h}$ of reaction. It is possible to observe that at $60{ }^{\circ} \mathrm{C}$ the bimodal distribution formed during the first part of the reaction is more pronounced in the RALLS and DV signals, remaining until the end. This behavior proves 


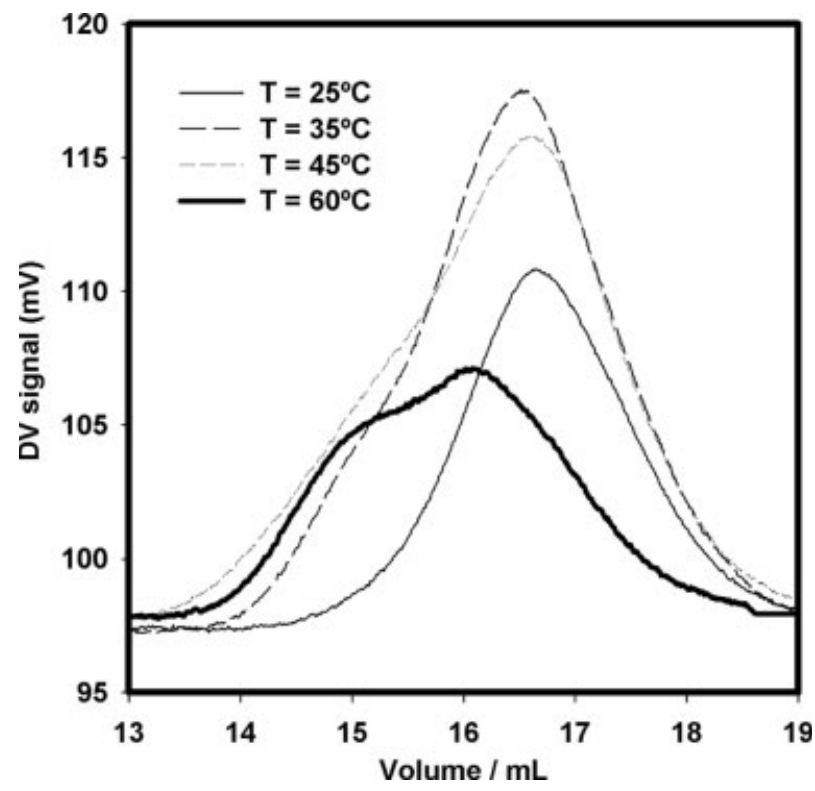

Figure 9. DV chromatogram obtained for the PBA polymer prepared under the following conditions: $[\mathrm{BA}]_{0} /$ $\left[\mathrm{CHI}_{3}\right]_{0} /\left[\mathrm{Na}_{2} \mathrm{~S}_{2} \mathrm{O}_{4}\right]_{0} /\left[\mathrm{NaHCO}_{3}\right]_{0}=25 / 1 / 4 / 1.45(\mathrm{~mol} / \mathrm{mol} /$ $\mathrm{mol} / \mathrm{mol}) ;[\mathrm{MF} 50] /[\mathrm{PVA} 88]=420 / 980(\mathrm{ppm} / \mathrm{ppm}, \mathrm{w} / \mathrm{w}$ relative to BA) at $25,35,45,60{ }^{\circ} \mathrm{C}$.

that two extremely different molecular weights are being formed during the reaction, otherwise a polymer with higher molecular weight than expected and a very broad chromatogram signal would be expected. The integration of the RI chromatogram signal that corresponds to the first peak presented in the DV or RALLS signals indicate that the region considered represents around $8 \%$ of the polymer that was detected in the RI. In the case of the polymer prepared at $35{ }^{\circ} \mathrm{C}$, the bimodal distribution was not detected.

For the specific mechanism presented in this work and considering other results published, ${ }^{8,9}$ it seems that the polymerization system loses it livingness due to iodine consumption (eq 6). The easiness of this side reaction is also a function of the monomer nature that might stabilize or not stabilize the iodine chain ends. For that reason, even considering that the diffusion of the radical anion $\mathrm{SO}_{2}^{--}$is controlled by equilibrium, which is also influenced by the temperature, between the water phase and the organic phase where the reaction proceeds. The maximum temperature possible to be used will be a combination of the amount of $\mathrm{Na}_{2} \mathrm{~S}_{2} \mathrm{O}_{4}$ and the temperature. The optimization of this process regarding the temperature can deeply determine the industrial potential of this methodology. Moreover, considering the low polymerization temperatures used and the high rate of DT involved in the process studied, it is possible to predict that the other side reactions are totally suppressed, especially for a monomer such as BA.

\section{Structural Analysis of the PBA by $500 \mathrm{MHz}{ }^{1} \mathrm{H}$ NMR Spectroscopy}

The NMR spectrum of the PBA obtained by SET-DTLRP of BA at $45{ }^{\circ} \mathrm{C}$ is shown in Figure 14. The spectra shows the signals of the four methylene groups (both main chain and butyl $-\mathrm{CH}_{2}-$ at $4.1,2.3,1.6$, and $1.4 \mathrm{ppm}$ ), methine group of the main chain $(-\mathrm{CH}-$ at $2.3 \mathrm{ppm})$. Methyl group of the butyl reveals the resonance at $0.9 \mathrm{ppm}$. Two other important signals are at 4.3 and $5.0 \mathrm{ppm}$. The resonance 4.3 belongs to the $-\mathrm{CH}_{2}-\mathrm{CHI}-\mathrm{CH}_{2}-$ derived from the $\mathrm{CHI}_{3}$ initiator, while the signal at $5.0 \mathrm{ppm}$ corresponds to $r$ and $m$ stereoisomers of $-\mathrm{CHIC}(\mathrm{O})$ $\mathrm{OBu}$ active chain ends. It should also be noted the absence of any peak at $5.2 \mathrm{ppm}\left(-\mathrm{CHI}_{2}\right)$ that may result from the initiation of only one iodine. ${ }^{8,12}$

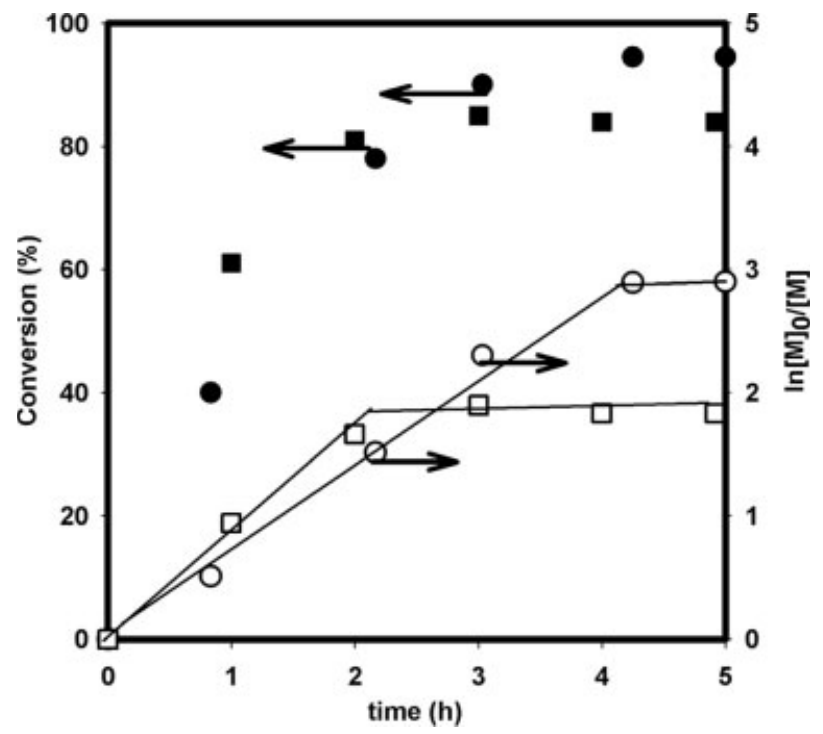

Figure 10. $\mathrm{Na}_{2} \mathrm{~S}_{2} \mathrm{O}_{4} / \mathrm{NaHCO}_{3}$-catalyzed LRP of BA initiated with iodoform in $\mathrm{H}_{2} \mathrm{O}$ in the presence of $\mathrm{SA}$ Methocel F50 and PVA 88, $[\mathrm{BA}] /\left[\mathrm{H}_{2} \mathrm{O}\right]=1 / 3(\mathrm{v} / \mathrm{v})$ for the following conditions: $[\mathrm{BA}]_{0} /\left[\mathrm{CHI}_{3}\right]_{0} /\left[\mathrm{Na}_{2} \mathrm{~S}_{2} \mathrm{O}_{4}\right]_{0} /\left[\mathrm{NaHCO}_{3}\right]_{0}$ $=250 / 1 / 4 / 1.45 \quad(\mathrm{~mol} / \mathrm{mol} / \mathrm{mol} / \mathrm{mol}) ;$ [Methocel F50]/ [PVA 88] $=420 / 980(\mathrm{ppm} / \mathrm{ppm}, \mathrm{w} / \mathrm{w}$ relative to BA $)$, at different temperatures: $(\bullet) 35{ }^{\circ} \mathrm{C}$ and (匹) $60{ }^{\circ} \mathrm{C}$. 


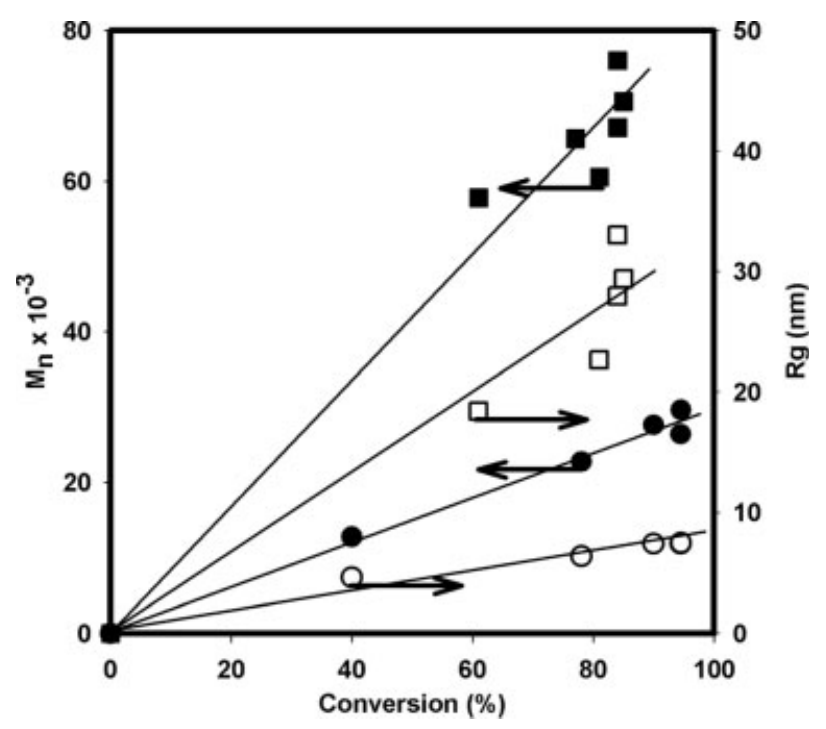

Figure 11. Dependence of molecular weight and $\mathrm{Rg}$ with the conversion for the $\mathrm{Na}_{2} \mathrm{~S}_{2} \mathrm{O}_{4} / \mathrm{NaHCO}_{3}$-catalyzed LRP of BA initiated with iodoform in $\mathrm{H}_{2} \mathrm{O}$ in the presence of SA Methocel F50 and PVA 88, [BA $]_{0} /$ $\left[\mathrm{H}_{2} \mathrm{O}\right]_{0}=1 / 3(\mathrm{v} / \mathrm{v})$ for the following conditions: [BA $]_{0} /$ $\left[\mathrm{CHI}_{3}\right]_{0} /\left[\mathrm{Na}_{2} \mathrm{~S}_{2} \mathrm{O}_{4}\right]_{0} /\left[\mathrm{NaHCO}_{3}\right]_{0}=250 / 1 / 4 / 1.45(\mathrm{~mol} /$ $\mathrm{mol} / \mathrm{mol} / \mathrm{mol}$ ); [Methocel F50]/[PVA 88] $=420 / 980$ $(\mathrm{ppm} / \mathrm{ppm}, \mathrm{w} / \mathrm{w}$ relative to $\mathrm{BA})$, at different temperatures: (๑) $35{ }^{\circ} \mathrm{C}$ and (ם) $60{ }^{\circ} \mathrm{C}$.

Table 3 presents the evolution of the ratio between the terminal iodines (active chain ends) and the middle iodine $\left(-\mathrm{CH}_{2}-\mathrm{CHI}-\mathrm{CH}_{2}\right)$ derived from the iodoform. The ratio was determined after 1 and $5 \mathrm{~h}$ of reaction. As expected for a DT process, it is clear the dependence between the amount of active chain ends $(-\mathrm{CHIC}(\mathrm{O}) \mathrm{OBu})$ and the reaction temperature. The increase in temperature leads to the loss of iodine chain ends. This result is extremely important since it opens the possibility to copolymerize acrylates with high molecular weight segments, without sacrifice the functionality of the $\alpha, \omega$-macroinitiator. When these results are compared to the TriSEC data, effectively they prove that the bimodal curves obtained at $60{ }^{\circ} \mathrm{C}$ (reaction temperature) are due to iodine consumption.

\section{SET-DTLRP of BA Initiated from $\alpha, \omega-\mathrm{Di}($ iodo)poly(BA)}

Figure 15 shows the RI chromatogram for the $\alpha, \omega$-di(iodo)poly(butyl acrylate) macroinitiator used to test the possibility to reinitiate the active iodo chain ends and the polymer obtained after the reinitation.
Figure 15 shows the total shift of the RI peak that belongs to the initial macroinitiator $\left(M_{\mathrm{n}}=\right.$ $10,859, M_{\mathrm{w}} / M_{\mathrm{n}}=2.15, \mathrm{Rg}=3.3 \mathrm{~nm}, \mathrm{Rg} / \mathrm{Rh}=$ $1.3, \eta=0.15 \mathrm{dL} / \mathrm{g})$ toward higher elution volumes, indicating that the polymer increased its molecular weight $\left(M_{\mathrm{n}}=94,283, M_{\mathrm{w}} / M_{\mathrm{n}}=2.13\right.$, $\mathrm{Rg}=16.6 \mathrm{~nm}, \mathrm{Rg} / \mathrm{Rh}=1.3, \eta=0.81 \mathrm{dL} / \mathrm{g})$. By this way, the living character of the PBA prepared by SET-DTLRP was confirmed.

The value obtained for the relation between $\mathrm{Rg} / \mathrm{Rh}$ is 1.3 , which indicates a random coil conformation for the PBA produced by SET/DTLRP.

\section{Viscosimetric Analysis}

Figure 16 shows the variation in the intrinsic viscosity with the $M_{\mathrm{w}}$ for the PBA prepared by SET/DTLRP. The selected points were obtained from seven PBA samples prepared at $25{ }^{\circ} \mathrm{C}$. The viscosity and the molecular weight are correlated by the following linear relationship:

$$
[\eta]=23.34 \times 10^{-4} M_{\mathrm{w}}^{0.86}
$$

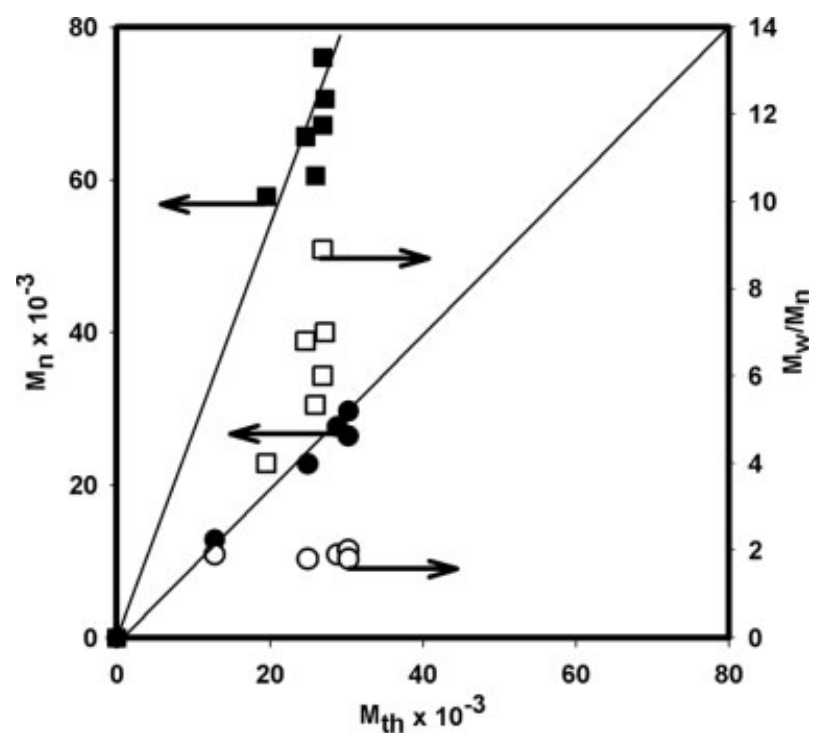

Figure 12. Dependence of molecular weight and polydispersity with the theoretically molecular weight for the $\mathrm{Na}_{2} \mathrm{~S}_{2} \mathrm{O}_{4} / \mathrm{NaHCO}_{3}$-catalyzed LRP of BA initiated with iodoform in $\mathrm{H}_{2} \mathrm{O}$ in the presence of $\mathrm{SA}$ Methocel F50 and PVA 88, $[\mathrm{BA}]_{0} /\left[\mathrm{H}_{2} \mathrm{O}\right]_{0}=1 / 3(\mathrm{v} / \mathrm{v})$ for the following conditions: $[\mathrm{BA}]_{0} /\left[\mathrm{CHI}_{3}\right]_{0} /\left[\mathrm{Na}_{2} \mathrm{~S}_{2} \mathrm{O}_{4}\right]_{0} /$ $\left[\mathrm{NaHCO}_{3}\right]_{0}=250 / 1 / 4 / 1.45(\mathrm{~mol} / \mathrm{mol} / \mathrm{mol} / \mathrm{mol})$; [MethocelF50]/[PVA 88] $=420 / 980(\mathrm{ppm} / \mathrm{ppm}, \mathrm{w} / \mathrm{w}$ relative to $\mathrm{BA})$, at different temperatures: ( $35{ }^{\circ} \mathrm{C}$ and $60{ }^{\circ} \mathrm{C}$.

Journal of Polymer Science: Part A: Polymer Chemistry 

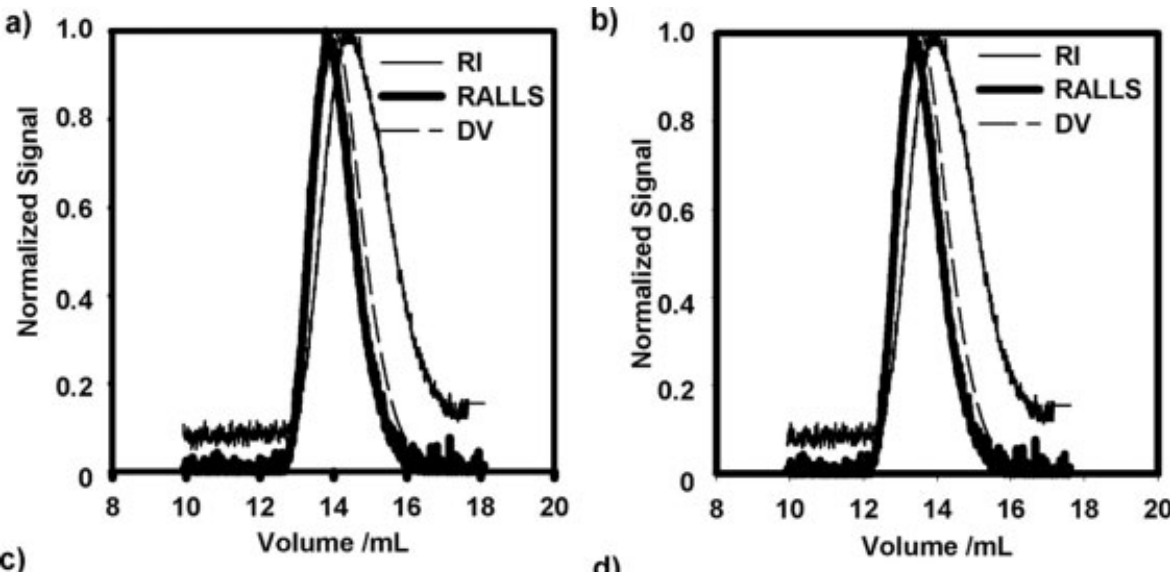

c)

d)
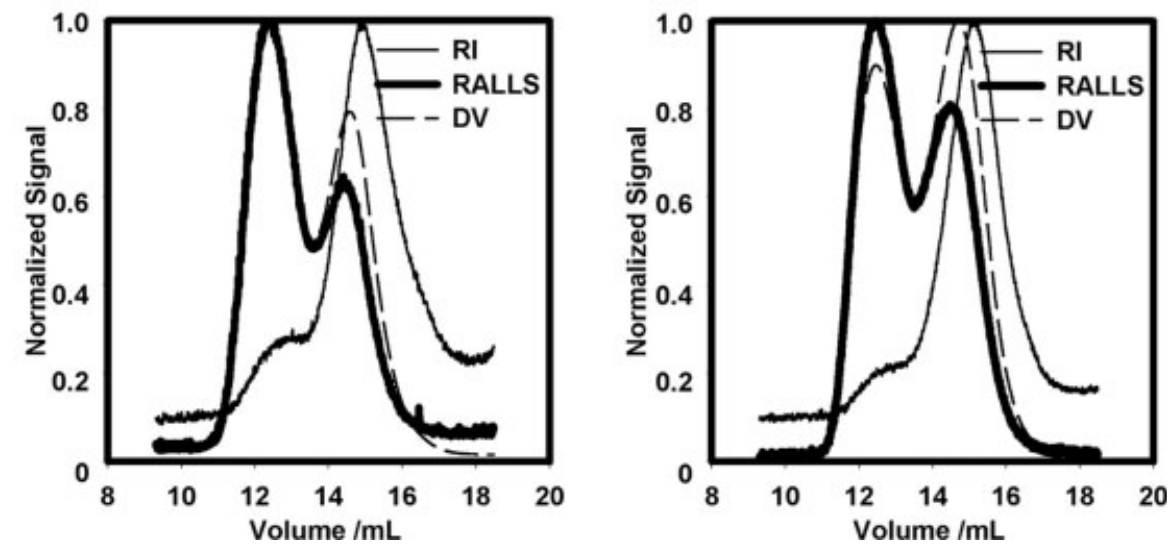

Figure 13. Evolution of the TriSEC chromatograms obtained for the $\mathrm{Na}_{2} \mathrm{~S}_{2} \mathrm{O}_{4} /$ $\mathrm{NaHCO}_{3}$-catalyzed LRP of BA initiated with iodoform in $\mathrm{H}_{2} \mathrm{O}$ in the presence of SA Methocel F50 and PVA 88, $[\mathrm{BA}]_{0} /\left[\mathrm{H}_{2} \mathrm{O}\right]_{0}=1 / 3(\mathrm{v} / \mathrm{v})$ for the following conditions: $[\mathrm{BA}]_{0} /\left[\mathrm{CHI}_{3}\right]_{0} /\left[\mathrm{Na}_{2} \mathrm{~S}_{2} \mathrm{O}_{4}\right]_{0} /\left[\mathrm{NaHCO}_{3}\right]_{0}=250 / 1 / 4 / 1.45 \quad(\mathrm{~mol} / \mathrm{mol} / \mathrm{mol} / \mathrm{mol}) ; \quad[$ Methocel $\mathrm{F} 50] /[\mathrm{PVA} 88]=420 / 980(\mathrm{ppm} / \mathrm{ppm}, \mathrm{w} / \mathrm{w}$ relative to $\mathrm{BA})$, at different temperature: (a) $35{ }^{\circ} \mathrm{C} 1 \mathrm{~h}$ reaction, (b) $35{ }^{\circ} \mathrm{C} 5 \mathrm{~h}$ reaction, (c) $60{ }^{\circ} \mathrm{C} 1 \mathrm{~h}$ reaction, (d) $60{ }^{\circ} \mathrm{C} 5 \mathrm{~h}$ reaction.

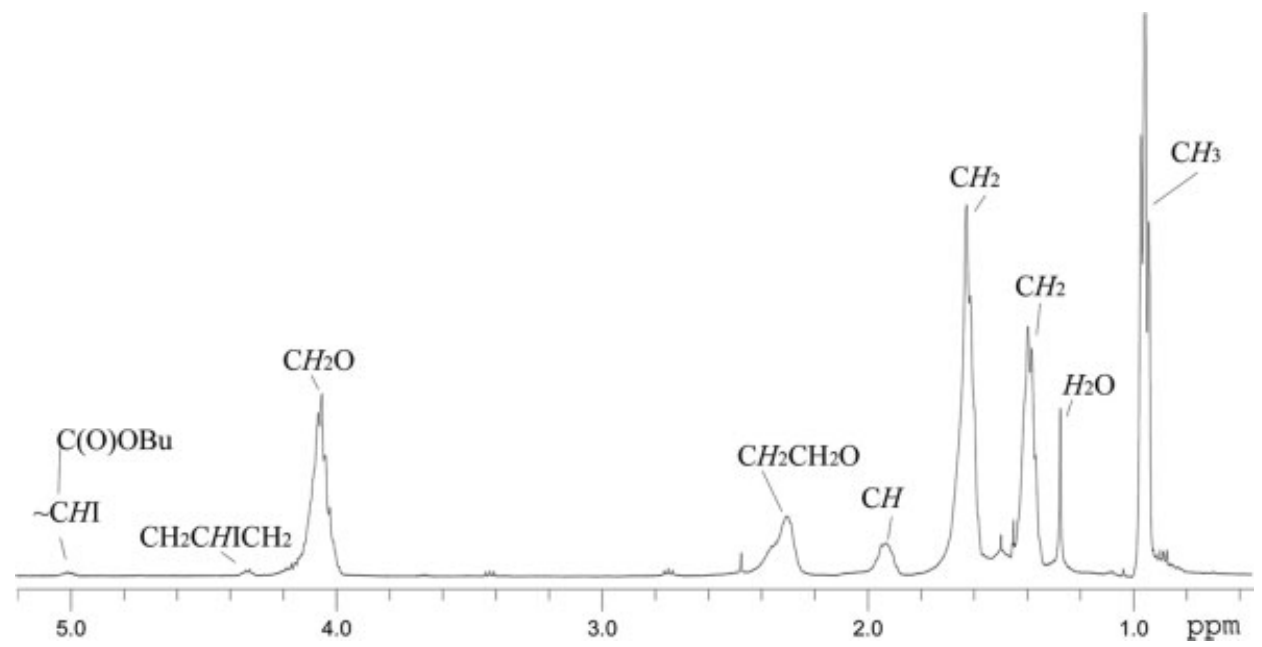

Figure 14. $500 \mathrm{MHz}{ }^{1} \mathrm{H} \mathrm{NMR}$ spectra in $\mathrm{CDCl}_{3}$ of obtained $\alpha, \omega$-di(iodo) PBA SETDTLRP at $45{ }^{\circ} \mathrm{C}$. 
Table 3. Viscosimetric and Structural Evaluation of $\alpha . \omega$-Di(iodo) PBA Prepared for Different Ratios $[\mathrm{BA}] /\left[\mathrm{CHI}_{3}\right]$ at Different Temperatures for $5 \mathrm{~h}$ of Reaction

\begin{tabular}{|c|c|c|c|c|c|c|c|c|}
\hline \multirow[b]{2}{*}{ No. } & \multirow[b]{2}{*}{$\mathrm{DP}$} & \multirow[b]{2}{*}{$\begin{array}{c}\text { Temperature } \\
\left({ }^{\circ} \mathrm{C}\right)\end{array}$} & \multirow[b]{2}{*}{$\begin{array}{c}\text { Conversion } \\
(\%)\end{array}$} & \multirow[b]{2}{*}{$\begin{array}{c}M_{\mathrm{n}} \text { th } \\
(\mathrm{Da})\end{array}$} & \multirow[b]{2}{*}{$\begin{array}{l}M_{\mathrm{n}, \mathrm{iTriSEC}} \\
\quad(\mathrm{Da})\end{array}$} & \multirow[b]{2}{*}{$M_{\mathrm{w}} / M_{\mathrm{n}}$} & \multicolumn{2}{|c|}{ Ratio } \\
\hline & & & & & & & $1 \mathrm{~h}^{\mathrm{a}}$ & $5 \mathrm{~h}$ \\
\hline \multirow[t]{4}{*}{1} & 25 & 25 & 95 & 3,044 & 3,128 & 2.5 & 1.8 & 1.5 \\
\hline & & 35 & 96 & 3,076 & 3,467 & 1.9 & 1.6 & 1.3 \\
\hline & & 45 & 94 & 3,011 & 4,135 & 2.5 & 1.4 & 1.2 \\
\hline & & 60 & 98 & 3,140 & 19.654 & 4.1 & 1.0 & 1.0 \\
\hline \multirow[t]{2}{*}{2} & 250 & 35 & 96 & 29,265 & 31,654 & 1.9 & 1.8 & 1.4 \\
\hline & & 60 & 80 & 25,630 & 70,564 & 3.9 & 1.1 & 1.0 \\
\hline
\end{tabular}

a $1 \mathrm{~h}$ of reaction.

The accuracy of the TriSEC equipment to determine the MHS constants relies on the direct measurements of $\eta$ and $M_{\mathrm{w}}$ directly from the detector signals, contrarily to other techniques available.

The scaling relationship between the $\mathrm{Rg}$ and $M_{\mathrm{w}}$ for PBA shown in Figure 17 reveals a linear relation along the whole range of $M_{\mathrm{w}}$ analyzed, and can be described mathematically by the relation

$$
\mathrm{R}_{\mathrm{g}}=K^{\prime} M^{\alpha^{\prime}}
$$

The power law exponent $\alpha^{\prime}$ is related to the shape adopted by the polymer chain in solution

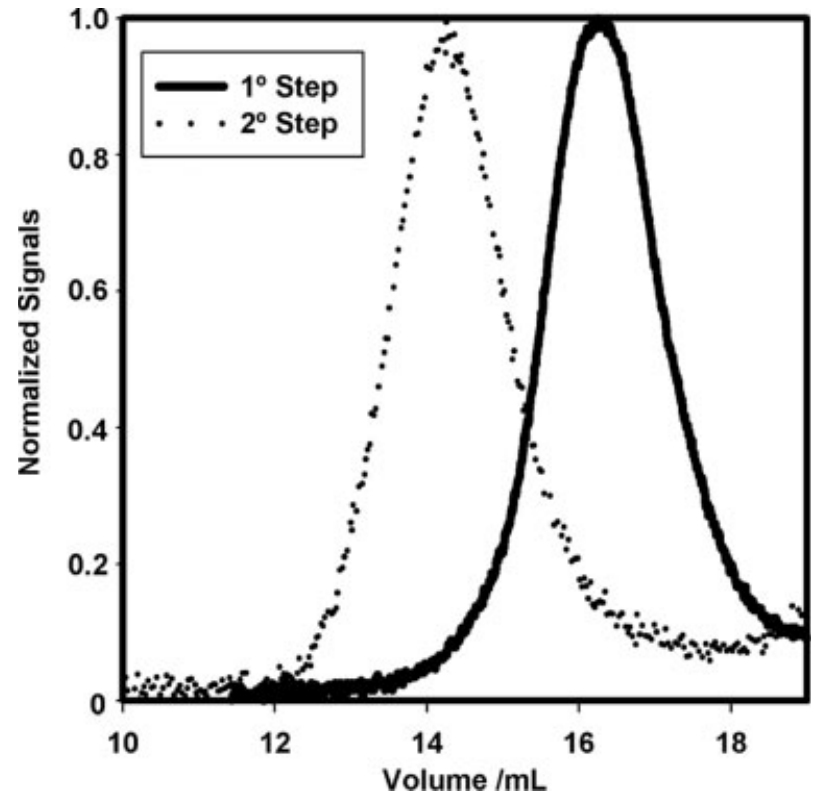

Figure 15. RI chromatogram for the $\alpha, \omega$-di(iodo)poly (butyl acrylate) macroinitiator and the resulting polymer prepared after $5 \mathrm{~h}$ of reaction. and yields information about the polymer-solvent interactions and macromolecular conformations of the polymer. For random coil conformation expected values are between $0.5-0.6$, that start in the polymer under $\theta$-conditions $(0.5)$ to polymer in very good solvents. Rigid rod polymers typically present values for this parameter as high as 1 , whereas spherical particles have a $\alpha^{\prime}$ equal to $1 / 3 .{ }^{23}$

The relationship follows the equation: $\mathrm{Rg}$ $=11.21 \times 10^{-3} M_{\mathrm{w}}^{0.6}$. This equation confirms again the random coil conformation of PBA in THF considering the values obtained for $\alpha^{\prime}$.

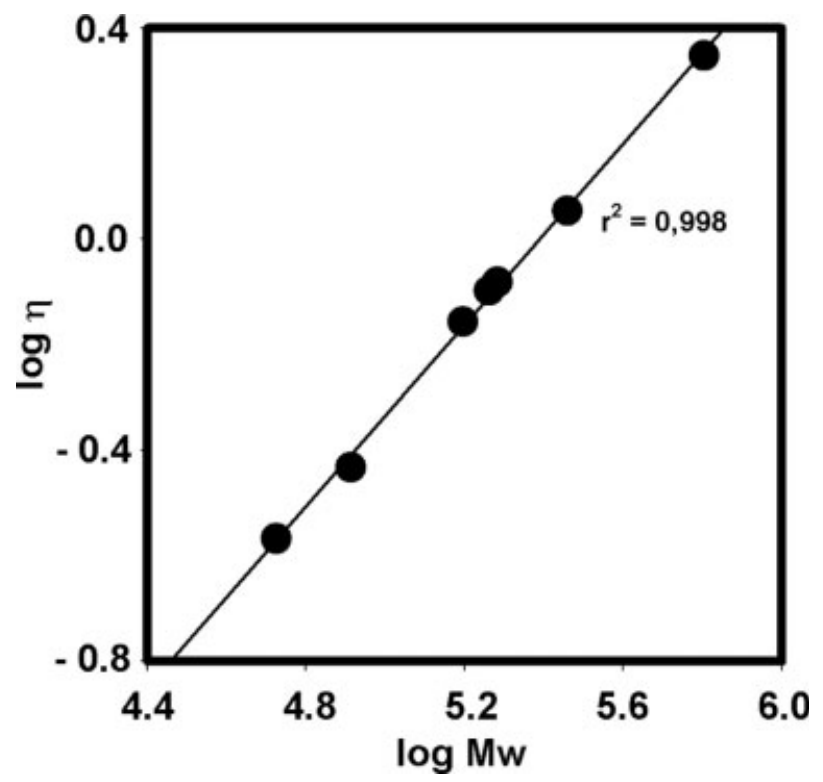

Figure 16. Plot of log (intrinsic viscosity) against $\log \left(M_{\mathrm{w}}\right)$ for PBA prepared by SET/DTLRP at $25{ }^{\circ} \mathrm{C}$ from which the Mark-Houwink-Sakaruda relationship was derived.

Journal of Polymer Science: Part A: Polymer Chemistry 


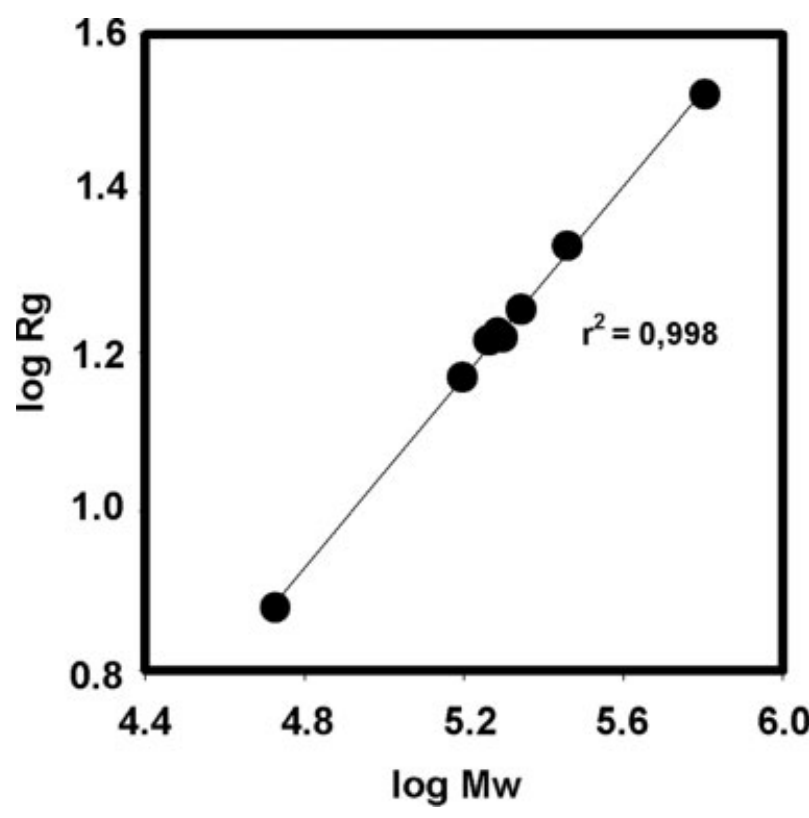

Figure 17. Plot of log radius of gyration against log molecular weight for PBA for PBA prepared by SET/ DTLRP at $35{ }^{\circ} \mathrm{C}$.

\section{Dynamic Mechanical Thermal Analysis and Thermogravimetric Analysis}

The thermal properties of the PBA samples were determined by DMTA and TGA. Figure 18 shows the traces obtained for PBA depending on the reaction temperature.

From the DMTA data, it can be observed that glass transition temperature does not change with polymerization temperature for the samples prepared until $45{ }^{\circ} \mathrm{C}$. For the PBA prepared at $60{ }^{\circ} \mathrm{C}$, two peaks of $\tan \delta$ in the region of $-41{ }^{\circ} \mathrm{C}$ are shown. Each peak corresponds to the wide different molecular weights fractions detected by TriSEC traces. The thermogravimetric curve shows no difference between the samples prepared in the range of temperature between 35 and $60{ }^{\circ} \mathrm{C}$.

\section{CONCLUSIONS}

The sodium dithionate-catalyzed polymerization of BA in water allowed preparation of PBA in a broad range of molecular weight. The iodoform proved to be an efficient initiator for the SETDTLRP of BA, yielding polymers with predetermined molecular weights in the range of 1000 $3,00,000$. The presence of iodine active chain ends was determined by ${ }^{1} \mathrm{H}$ NMR spectroscopy.

Journal of Polymer Science: Part A: Polymer Chemistry DOI 10.1002/pola
This methodology was carried out under feasible conditions to be scaled-up for industrial purposes. The $\alpha, \omega$-di(iodo) poly(butyl acrylate) macroinitiators can be used for further reinitiation leading to the preparation of tailor-made polymers with complex architectures. Even at the lowest temperatures studied in this work, it was possible to obtain fast reaction rates. This feature constitutes an important advantage from the industrial standpoint. Additionally, other progresses achieved with this SET-DTLRP methodology are extremely important for industrial scale, comparing to other living radical polymerization processes, such as the absence of any organic solvent, the fast polymerization rates, the large scale availability and easiness to handle the compounds used in the SET-DTLRP of PBA.

\section{EXPERIMENTAL}

\section{Materials}

The tetrahydrofuran HPLC-grade uninhibited, alumina oxide, iodoform (99\%), sodium dithionate $(85 \%)$ sodium bicarbonate $(99 \%)$, and $\mathrm{BA}$ were purchased from Sigma-Aldrich. The BA was purified through a basic $\mathrm{Al}_{2} \mathrm{O}_{3}$ column. The Polystyrene standards were purchased from Polymer Laboratories. The hydroxypropyl methylcellulose-Methocel F50 (MF50) was purchased from Dow Chemical Company. The partial hydrolyzed

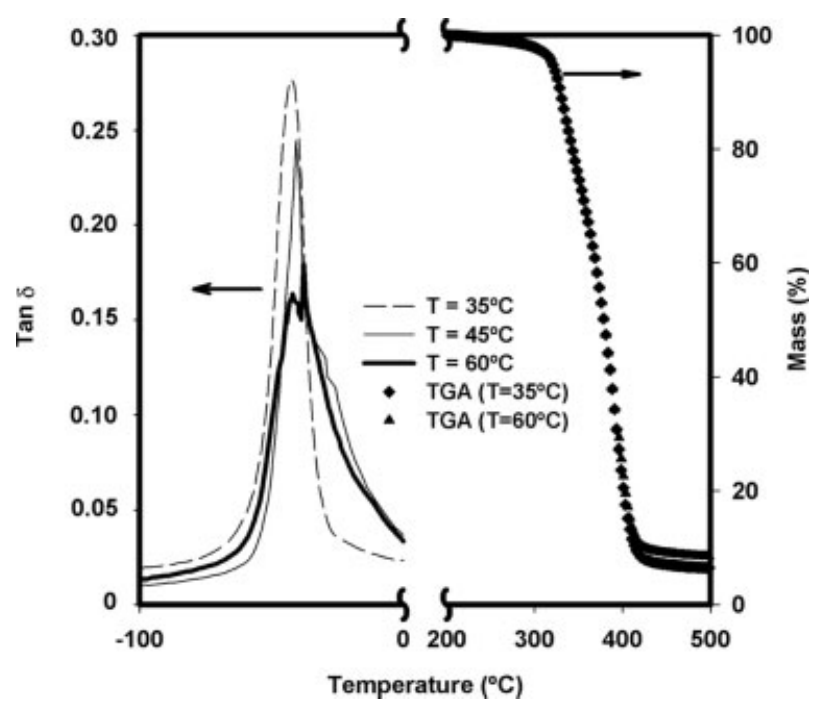

Figure 18. DMTA/TGA thermograms for PBA prepared at different temperatures. 
poly(vinyl alcohol) (PVA) was purchased from Syntomer.

\section{Polymerization of $\mathrm{nBA}$ via SET/DTLRP}

The typical procedure was performed as described (example ratio $[\mathrm{VC}] /\left[\mathrm{CHI}_{3}\right]=100$ ). In a $50-\mathrm{mL}$ Ace Glass $8645 \# 15$ pressure tube equipped with bushing and plunger valve was introduced $9 \mathrm{~mL}$ of desionized water, $43.12 \mathrm{mg}$ of a $3 \%$ PVA solution $(490 \mathrm{ppm})$ and $29.81 \mathrm{mg}$ of a $1.86 \%$ MF50 solution $(210 \mathrm{ppm})$. The content was stirred and bubbled with nitrogen during $10 \mathrm{~min}$. The other compounds were then weighted, catalyst $\left(\mathrm{Na}_{2} \mathrm{~S}_{2} \mathrm{O}_{4}\right.$, $143.4 \mathrm{mg}$ ), initiator $\left(\mathrm{CHI}_{3}, 81.10 \mathrm{mg}\right)$, buffer $\left(\mathrm{NaHCO}_{3}, 25.1 \mathrm{mg}\right.$ ), additive (sodium $p$-toluene sulfonate, pTsNa, $80.8 \mathrm{mg}$ ) and $3 \mathrm{~mL}$ of purified BA were added. The tube was closed, frozen in $\mathrm{MeOH} / \mathrm{dry}$ ice and degassed through the pluger valve by applying circles of reduced pressure followed by filling the tube with inert gas for 20 times at $-40{ }^{\circ} \mathrm{C}$. The valve was closed and the reaction was kept in a controlled temperature water bath for $1 \mathrm{~h}$ at $35{ }^{\circ} \mathrm{C}$. At the end of the reaction, a small liquious part was taken for TriSEC measurements. The polymer was placed in a preweighted vial and the remaining part of the tube was carefully washed with THF and placed in a different vial. After drying in a vacuum oven until constant weight, both vials were weighted to determine the final conversion.

\section{Reinitiation of PBA-Active Chain Ends}

This experiment was performed using an $\alpha, \omega$ di(iodo) PBA (Table 3). This polymer was previously synthesized following the procedure described earlier, washed with deionized water and dried under vacuum at $25{ }^{\circ} \mathrm{C}$ until constant weight. Two grams of $\alpha, \omega$-di(iodo) PBA macroinitiator $(0.184 \mathrm{mmol}), 253.5 \mathrm{mg}$ of $\mathrm{Na}_{2} \mathrm{~S}_{2} \mathrm{O}_{4}$ (1.45 $\mathrm{mmol}), 30.5 \mathrm{mg}$ of $\mathrm{NaHCO}_{3}(0.727 \mathrm{mmol}), 142.7 \mathrm{mg}$ of $\mathrm{pTsNa}(0.727 \mathrm{mmol})$ and $17.5 \mathrm{~g}$ of $\mathrm{BA}$ $(136.5 \mathrm{mmol})(\mathrm{DP}=750)$ were added to a glass reactor. The reaction time was $5 \mathrm{~h}$ at $35{ }^{\circ} \mathrm{C}$. The final polymer was recovered and analyzed (17.06 g, $87.5 \%)$.

\section{Sample Preparation for Size Exclusion Chromatography}

Around $40 \mathrm{mg}$ of PBA were allowed to complete dissolution in a dilution flask of $10 \mathrm{~mL}$ over $24 \mathrm{~h}$. The solution was passed through a basic $\mathrm{Al}_{2} \mathrm{O}_{3}$ column, precipitated in water and filtered under vacuum. The polymer was then dried in the oven at $40{ }^{\circ} \mathrm{C}$ under vacuum until constant weight was reached. Approximately $20 \mathrm{mg}$ of PBA were dissolved in $10 \mathrm{~mL}$ of THF under stirring during $24 \mathrm{~h}$. The exact concentration was determined considering the weight measured and the $10 \mathrm{~mL}$ of solvent used (all the samples were prepared with concentrations around $2 \mathrm{mg} / \mathrm{mL}$ ).

\section{Characterization Techniques}

The chromatography parameters of the samples were determined using a HPSEC; Viscotek (Dual detector 270, Viscotek, Houston) with a differential viscometry (DV); right-angle laser light scattering (RALLS, Viscotek) and RI (Knauer K-2301). The column set consisted of a PL $10-\mu \mathrm{m}$ guard column $\left(50 \times 7.5 \mathrm{~mm}^{2}\right)$ followed by two MIXED-B PL columns $\left(300 \times 7.5 \mathrm{~mm}^{2}\right.$, $10 \mu \mathrm{m}$ ). HPLC pump (Knauer K-1001) was set with a flow rate of $1 \mathrm{~mL} / \mathrm{min}$. The eluent (THF) was previously filtered through a $0.2 \mu \mathrm{m}$ filter. The system was also equipped with a Knauer online degasser. The tests were done at $30{ }^{\circ} \mathrm{C}$ using an Elder $\mathrm{CH}-150$ heater. Before the injection $(100 \mu \mathrm{L})$ the samples were filtered through a PTFE membrane with $0.2 \mu \mathrm{m}$. The system was calibrated with narrow polystyrene standards. The differential refractive index $(\mathrm{d} n / \mathrm{d} c)$ for $670 \mathrm{~nm}$ was $0.0651 \pm 0.0004$ depending on the $M_{\mathrm{w}}$ of PBA. The analysis of light scattering data by Viscotek's software was done assuming that the second virial coefficient was zero, considering the low solution concentrations used in this work. The ${ }^{1} \mathrm{H}$ NMR spectra $(500 \mathrm{MHz})$ were recorded in a Bruker DRX 500 spectrometer at $32{ }^{\circ} \mathrm{C}$ in $\mathrm{CDCl}_{3}$ with tetramethylsilane (TMS) as internal standard. Dynamical mechanical thermal analysis (DMTA) of thick specimens (15.20 $\mathrm{mm} \times 7.45 \mathrm{~mm} \times 1.2 \mathrm{~mm}$ ) were performed using a Triton Tritec 2000 in the Constrain Layer Damping mode using a frequency of $1 \mathrm{~Hz}$, with a standard heating rate of $2{ }^{\circ} \mathrm{C} \mathrm{min}{ }^{-1}$. The $T_{\mathrm{g}}$ was determined as the peak in $\tan \delta$ (Tan $\delta$ $\left.=E^{\prime \prime} / E^{\prime}\right)$ where $E^{\prime \prime}$ and $E^{\prime}$ are the loss and storage modulus, respectively. The TGA curves were obtained using a Netzsch STA 449C Jupiter and the tests were carried out at $5{ }^{\circ} \mathrm{C} / \mathrm{min}$.

\section{Calculation of Intrinsic Viscosity [ $\eta]$ and Molecular Weight $\mathbf{M}_{\mathrm{w}}$}

The parameters presented in this work $\left(M_{\mathrm{n}}\right.$, number average molecular weight; $M_{\mathrm{w}}$, weight 
average molecular weight; $\eta$, intrinsic viscosity; $\mathrm{Rg}$, gyration radius; $\mathrm{Rh}$, hydrodynamic radius, and $\mathrm{d} n / \mathrm{d} c$, refractive increment index) were calculated using the TriSEC software provided by Viscotek (version 3.0). The algorithm applied in the software is briefly described in literature, ${ }^{23}$ and it will not be repeated here again. It should also be referred that the software monitors the elution times of the RALLS, DV, and RI detectors and adjusts the volume calculation according to the RI detector.

\section{REFERENCES AND NOTES}

1. Coca, S.; Jasieczek, C. B.; Beers, K. L.; Matyjaszewsi, K. J Polym Sci Part A: Polym Chem 1998, 36, 1417-1424.

2. Shipp, D. A.; Wang, J.-L.; Matyjaszewski, K. Macromolecules 1998, 31, 8005-8008.

3. Matyjaszewski, K.; Nakagawa, Y.; Jasieczek, C. B. Macromolecules 1998, 31, 1535-1541.

4. Fuji, Y.; Ando, T.; Kamigaito, M.; Sawamoto, M. Macromolecules 2002, 35, 2949-2954.

5. Farcet, C.; Charleux, B.; Pirri, R. Macromolecules 2001, 34, 3823-3826.

6. Georges, M. K.; Lukkarila, J. L.; Szkurhan, A. R. Macromolecules 2004, 37, 1297-1303.

7. Percec, V.; Popov, A. V.; Ramirez-Castilho, E.; Monteiro, M.; Barboiu, B.; Weichold, O.; Asandei, A. D.; Mitchell, C. M. J Am Chem Soc 2002, 124, 4940, 4941.

8. Percec, V.; Popov, A. V.; Ramirez-Castilho, E.; Weichold, O. J Polym Sci Part A: Polym Chem 2003, 41, 3283-3299.

9. Percec, V.; Popov, A. V.; Ramirez-Castilho, E.; Coelho, J. F. J.; Hinojosa-Falcon, L. A. J
Polym Sci Part A: Polym Chem 2004, 42, 6267-6282.

10. Percec, V.; Guliashvili, T.; Popov, A. V.; RamirezCastilho, E. J Polym Sci Part A: Polym Chem 2005, 43, 1478-1486.

11. Percec, V.; Guliashvili, T.; Popov, A. V. J Polym Sci Part A: Polym Chem 2005, 43, 1948-1954.

12. Percec, V.; Ramirez-Castilho, E.; Popov, A. V.; Hinojosa-Falcon, L. A.; Guliashvili, T. J Polym Sci Part A: Polym Chem 2005, 43, 2178-2184.

13. Percec, V.; Popov, A. V.; Ramirez-Castilho, E.; Weichold, O. J Polym Sci Part A: Polym Chem 2004, 42, 6364-6374.

14. Percec, V.; Guliashvili, T.; Popov, A. V. (University of Pennsylvania). U.S. Pat. Appl.0,131,186, 2005. Chem Abstr 2005, 143, 60398.

15. Iovu, M. C.; Matyjaszewski, K. Macromolecules 2003, 36, 9346-9354.

16. Huang, Y.; Peng, H.; Lam, J. W. Y.; Xu, Z.; Leung, F. S. M.; Mays, J. W.; Tang, B. Z. Polymer 2004, 45, 4811-4817.

17. Huang, Y.; Xu, Z.; Ma, D.; Yang, J.; Mays, J. W. Int J Polym Anal Charact 2003, 8, 383-394.

18. Huang, Y.; Lujia, B.; Lewei, B.; Dezhen, Z.; Chengwei, S.; Zhongde, X.; Yip, L. W.; Benzhong, T.; Jimmy, M. W. Polym Bull 2000, 44, 539-546.

19. Morey, T. H.; Coll, H. J Appl Polym Sci 1995, 56, 65-72.

20. Tortosa, K.; Smith, J.-A.; Cunningham, M. F. Macromol Rapid Commun 2001, 22, 957-961.

21. Coelho, J. F. J.; Gonçalves, P. M. F. O.; Miranda, D.; Gil, M. H. Eur Polym J 2006, 42, 751-763.

22. Percec, V.; Popov, A. V. J Polym Sci Part A: Polym Chem 2005, 43, 1255-1260.

23. Beer, M. U.; Wood, P. J.; Weisz, J. Carbohydr Polym 1999, 39, 377-380. 